\title{
Leishmania Hijacks Myeloid Cells for Immune Escape
}

\begin{abstract}
María Martínez-López ${ }^{1}$, Manuel Soto², Salvador Iborra ${ }^{1,3 *}$ and David Sancho ${ }^{1 *}$
${ }^{1}$ Immunobiology Laboratory, Fundación Centro Nacional de Investigaciones Cardiovasculares "Carlos III", Madrid, Spain, ${ }^{2}$ Departamento de Biología Molecular, Centro de Biología Molecular Severo Ochoa - Consejo Superior de Investigaciones Científicas-Universidad Autónoma de Madrid, Madrid, Spain, ${ }^{3}$ Department of Immunology, Complutense University School of Medicine and 12 de Octubre Health Research Institute (imas12), Madrid, Spain
\end{abstract}

Protozoan parasites of the Leishmania genus are the causative agents of leishmaniasis, a group of neglected tropical diseases whose clinical manifestations vary depending on the infectious Leishmania species but also on host factors. Recognition of the parasite by host myeloid immune cells is a key to trigger an effective Leishmaniaspecific immunity. However, the parasite is able to persist in host myeloid cells by evading, delaying and manipulating host immunity in order to escape host resistance and ensure its transmission. Neutrophils are first in infiltrating infection sites and could act either favoring or protecting against infection, depending on factors such as the genetic background of the host or the parasite species. Macrophages are the main host cells where the parasites grow and divide. However, macrophages are also the main effector population involved in parasite clearance. Parasite elimination by macrophages requires the priming and development of an effector Th1 adaptive immunity driven by specific subtypes of dendritic cells. Herein, we will provide a comprehensive outline of how myeloid cells regulate innate and adaptive immunity against Leishmania, and the mechanisms used by the parasites to promote their evasion and sabotage. Understanding the interactions between Leishmania and the host myeloid cells may lead to the development of new therapeutic approaches and improved vaccination to leishmaniases, an important worldwide health problem in which current therapeutic or preventive approaches are limited.

Keywords: myeloid cell, Leishmania, immune escape, neutrophils, macrophages, dendritic cells

\section{INTRODUCTION}

The trypanosomatid protozoa Leishmania spp. belonging to the order kinetoplastida are the causative agents of leishmaniases, whose clinical manifestations can range from cutaneous, mucocutaneous or diffuse cutaneous forms to visceral forms, depending on both the parasite species and the host's immune response (Pace, 2014). Leishmania is a digenetic parasite, whose life cycle involves two hosts, the insect vector and a vertebrate host. Leishmania parasites are transmitted to the vertebrate host by the bite of infected female sandflies belonging to the genera Phlebotomus and Lutzomyia (Akhoundi et al., 2016). Inside the sandflies the extracellular flagellated, motile form, called procyclic promastigotes generate the infective, non-dividing metacyclic promastigotes, which are inoculated into the host during blood feeding. Once there, Leishmania become into the aflagellate intracellular form, called amastigotes, that undergo 
replication within host cells, mainly phagocytes such as macrophages. The transmission cycle is complete when infected phagocytes are taken up during a sandfly blood meal, and amastigotes then convert into promastigotes in the sandfly midgut. As a successful parasite, Leishmania has developed strategies to evade host immune mechanisms in order to survive within the host. The ability of Leishmania to maintain a chronic infectious state within its host depends largely on its immune evasion potential (Geiger et al., 2016). We will review how myeloid cells drive innate and adaptive immunity against Leishmania and how the parasites escape host resistance.

\section{INNATE AND ADAPTIVE IMMUNITY AGAINST Leishmania}

The generation of protective immunity against Leishmania requires the cooperation between the innate and adaptive host immune cells. Clearance of Leishmania parasites that promotes healing requires IFN- $\gamma$-producing effector cells, mainly CD4 ${ }^{+} \mathrm{T}$ helper 1 (Th1). IFN- $\gamma$ production by NK cells (Bajenoff et al., 2006) and type $1 \mathrm{CD}^{+} \mathrm{T}$ cells (Belkaid et al., 2002b) also correlates with protection against L. major in mice, whereas $\mathrm{CD}^{+} \mathrm{T}$ cells play an important role in controlling visceral leishmaniasis (Stäger and Rafati, 2012). However, cytotoxic T lymphocytes (CTLs) play a detrimental role during infection with other Leishmania species, such as L. braziliensis (Novais and Scott, 2015). IFN- $\gamma$ signaling in infected macrophages promotes expression of inducible nitric oxide (NO) synthase (iNOS, NOS2) and NO production that, together with reactive oxygen species (ROS) generated during phagocytosis, are essential to kill intracellular parasites (Bogdan et al., 1990; Green et al., 1990). However, L. amazonensis are resistant to IFN- $\gamma$-mediated killing, and parasite control during the early stages of infection in mice is independent of this cytokine (Kima and Soong, 2013). Besides IFN- $\gamma$, other inflammatory cytokines, such as TNF, can activate the infected macrophages in an autocrine manner to produce NO (Bronte and Zanovello, 2005). On the contrary, $\mathrm{CD} 4{ }^{+} \mathrm{T}$ helper 2 (Th2)-related cytokines, such as IL-4, IL-13, IL-10, and antibody production are associated with alternative activated macrophages (Gordon, 2003), which favors parasite survival inside the macrophages (Kropf et al., 2005), and a non-healing phenotype (Scott et al., 1988; Heinzel et al., 1989; Chatelain et al., 1992; Sacks and Noben-Trauth, 2002).

Although macrophages are the primary host cell for Leishmania parasites, monocytes, dendritic cells (DCs) and neutrophils can be infected and contribute differentially to the immune response and the outcome of the infection. Acting as a bridge between innate and adaptive immune system, DCs have a prominent role for the development of immune response against the parasite. Leishmania infection of DCs results in IL-12 production (Marovich et al., 2000), an essential cytokine for the polarization of naive $\mathrm{T}$ cells toward Th1 subset and subsequent IFN- $\gamma$ production to control the infection (Heinzel et al., 1993; Sypek et al., 1993; von Stebut et al., 1998). DCs derived from inflammatory monocytes (moDCs) and the migratory
$\mathrm{CD} 03^{+}$DCs are the main source of IL-12 upon Leishmania infection (Leon et al., 2007; Martinez-Lopez et al., 2015).

Leishmania infection resolution generates a long-lasting immunity to reinfection mediated primarily by a population of short-lived Leishmania-specific effector $\mathrm{CD} 4^{+} \mathrm{T}$ cells maintained by low number of parasites that persist after resolution (Peters et al., 2014). Apart from this, Leishmania-specific effector memory T (TEM) cells and central memory T (TCM) cells are detected upon Leishmania infection (Zaph et al., 2004; Colpitts et al., 2009). Only TCM cells can proliferate, differentiate into effector $\mathrm{T}$ cells, and migrate to the lesion site, protecting the host against the infection (Zaph et al., 2004). In addition, $\mathrm{CD}^{+}{ }^{+} \mathrm{T}$ resident memory cells (TRM) have been identified at sites distant from the primary lesion in L. major immune mice and increase the ability of circulating effector cells to mediate protection against the infection (Glennie et al., 2015). After resolution of infection, there are also $\mathrm{CD}^{+} \mathrm{T}$ cells, which can contribute to host protection after reinfection or vaccination (Gurunathan et al., 1997; Muller et al., 1997; Rhee et al., 2002; Colmenares et al., 2003; Jayakumar et al., 2011). Understanding how parasites subvert the host innate immune response could help to target these mechanisms in future vaccine strategies that promote more effective and longer-term protection in leishmaniasis mediated by these TCM and TRM cells.

\section{Leishmania TARGETING NEUTROPHILS AS FIRST LINE OF DEFENSE}

Neutrophils are recruited early after Leishmania infection in response to several factors derived from the host, the sand fly, or the parasite itself. These cells contribute to kill the invading pathogens by formation of neutrophil extracellular traps (NETs) or by a potent oxidative burst generation and granule-derived toxic compound secretion in the surrounding environment or into the phagosome (Kolaczkowska and Kubes, 2013). Neutrophils from visceral leishmaniasis patients are highly activated and degranulated (Yizengaw et al., 2016). In addition, CCL3 secreted by neutrophils also attracts monocytes to the site of infection in an experimental model of $L$. major infection (Charmoy et al., 2010b). However, depending on the parasite species and the host, neutrophils can contribute to parasite elimination, or, conversely, favor immune escape by the parasite (Carlsen et al., 2015; de Menezes et al., 2016; Hurrell et al., 2016). Notably, the parasite itself can cause a delay in neutrophil apoptosis that allows parasite replication within these cells (see Regli et al., 2017 for a recent review on how Leishmania parasites are able to survive into these myeloid cells).

\section{NETs in Leishmania Infection}

Neutrophils release NETs composed by granule proteins together with chromatin that form extracellular fibers that can kill microorganisms (Brinkmann et al., 2004). This process can be ROS-dependent and concludes with the death of the neutrophil by a process named NETosis (Fuchs et al., 2007; Kirchner et al., 2012). In addition, there is a ROS-independent early NETosis 
(Pilsczek et al., 2010). Leishmania promastigotes induce both types of NET formation in human and mouse neutrophils both in vitro and in vivo (Figure 1A) (Rochael et al., 2015; Regli et al., 2017). Depending on the species, some promastigotes are resistant to NET-mediated killing as described for L. mexicana in mice and L. donovani in humans, while others are susceptible as demonstrated for $L$. amazonensis in response to human neutrophils, and this is dependent on lipophosphoglycan (LPG), a glycolipid molecule abundantly found in the surface of the promastigote forms (Guimaraes-Costa et al., 2009; Gabriel et al., 2010; Hurrell et al., 2015). Moreover, Leishmania can escape from NET-mediated killing, through the expression of nucleases, as well as by the presence of endonuclease (Lundep) in the vector's saliva, allowing parasites to survive (Figure 1B), as occurred in the interaction between L. infantum and L. major and human neutrophils (Chagas et al., 2014; Guimaraes-Costa et al., 2014). On the other hand, NETs formation in response to Leishmania can interfere with the generation of adaptive immunity, given that NETs isolated from human neutrophils activated by $L$. amazonensis promastigotes are able to inhibit monocyte-derived DCs differentiation and function, thus favoring parasite survival (Barrientos et al., 2014; Guimaraes-Costa et al., 2017).

\section{Inhibition of Neutrophil-Mediated Oxidative Burst}

Leishmania promastigote has evolved to survive within neutrophils following phagocytosis. Promastigotes from some Leishmania species like L. donovani or L. major express particular molecules, like LPG, that inhibit phagosome maturation (Gueirard et al., 2008; Mollinedo et al., 2010). In addition, others molecules from $L$. donovani, like tartrate-resistant acid phosphatase (ACP) and Leishmania chemotactic factor (LCF) inhibit the respiratory burst, (Figure 1C) (Remaley et al., 1984; Al Tuwaijri et al., 1990; Wenzel and Van Zandbergen, 2009). LCF from some Leishmania species, including L. major, L. aethiopica, and L. donovani, shares features of both $\mathrm{LTB}_{4}$ and $\mathrm{LXA}_{4}$ mediators. Similar to $\mathrm{LTB}_{4}$, LCF contributes to increased neutrophil recruitment in vitro either directly or by inducing IL-8 secretion by neutrophils (Figure 1D). Similar to LXA 4 , LCF from the cited species, increases parasite engulfment and survival within neutrophils in vitro through the inhibition of oxidative burst, mediating its effects via the $\mathrm{LXA}_{4}$ receptor (ALX/FPRL-1) (Figure 1E) (van Zandbergen et al., 2002). In line with this, L. major-infected neutrophils release an increased amount of $\mathrm{LTB}_{4}$, whereas $\mathrm{LXA}_{4}$ production is reduced, contributing to the initial establishment of the infection (Plagge and Laskay, 2017). On the other hand, the presence of apoptotic cells at the site of infection could contribute to the parasite evasion of the oxidative-mediated killing, since apoptotic cells promote L. major survival within neutrophils by downregulating ROS production (Figure 1F) (Salei et al., 2017).

\section{Extending Neutrophil Lifespan}

Neutrophils could be considered non-suitable host cells for intracellular parasites due to their short lifespan. Notwithstanding, Leishmania infection increases the survival of neutrophils both in vitro and in vivo (Aga et al., 2002). L. major increases neutrophil lifespan by activation of ERK1/2 and induction of anti-apoptotic proteins Bcl-2 and Bfl-1 (Figure 1G) (Sarkar et al., 2013). However, the neutrophil response to Leishmania infection may depend on its location, since L. major delays mouse peritoneal and human blood-derived neutrophil apoptosis (Aga et al., 2002; Charmoy et al., 2010a), but this apoptosis delay is not observed in infected mouse dermal neutrophils (Ribeiro-Gomes et al., 2012).

\section{MACROPHAGES AS KEY HOSTS AND EFFECTORS AGAINST Leishmania}

Leishmania infects macrophages directly after being released from neutrophils (Peters et al., 2008) or following the phagocytosis of apoptotic neutrophils containing intact parasites. The later mechanism mediates a silent transmission of Leishmania promastigotes to macrophages and couples to the triggering of an anti-inflammatory response associated to uptake of apoptotic cells, with TGF- $\beta$ secretion, which favors the survival and division of parasites within the macrophages in a model of transmission so that called "Trojan Horse" (Figure 1H) (Laskay et al., 2003, 2008; John and Hunter, 2008). MIP-1 $\beta$ secretion by infected neutrophils favors attraction of macrophages to the site of the infection (van Zandbergen et al., 2004). This process requires Leishmania-mediated neutrophil apoptosis, which does not occur in all species (Hurrell et al., 2015). In addition, in vivo imaging revealed that parasites can also escape dying neutrophils to infect macrophages, which was termed the 'Trojan rabbit' strategy (Ritter et al., 2009). Once inside macrophages, Leishmania amastigotes differentiate and multiply, which requires manipulating macrophage function to escape ROS generation and the action of lysosomal enzymes and the acidic milieu of the phagolysosome. In addition, parasites modulate the cytokine repertoire secreted by the infected macrophages and their ability to act as antigen presenting cells, in order to avoid a proper generation of the adaptive immune response (de Menezes et al., 2016).

\section{Interfering Phagosome Maturation in Macrophages}

Leishmania parasites delay phagosome formation and maturation, as shown by hindered expression of late endosomal markers LAMP-1 and Rab7, as occurred with L. donovani (Figure 2A) (Scianimanico et al., 1999; Seguin and Descoteaux, 2016). In addition, some Leishmania (such as L. amazonensis and L. mexicana) promote the formation of large parasitophorous vacuoles by the lysosomal trafficking protein to dilute the leishmanicidal effect of NO (Wilson et al., 2008). Several factors from the parasite participate in this evasion strategy, depending on the different Leishmania species. L. donovani LPG prevents the assembly of the NADPH oxidase complex (Figure 2B) (Lodge et al., 2006), excludes the proton-ATPase from the phagosome (Vinet et al., 2009), and reduces its fusion with the endosome (Desjardins and Descoteaux, 1997; Scianimanico et al., 1999), what has also been demonstrated for L. major LPG 


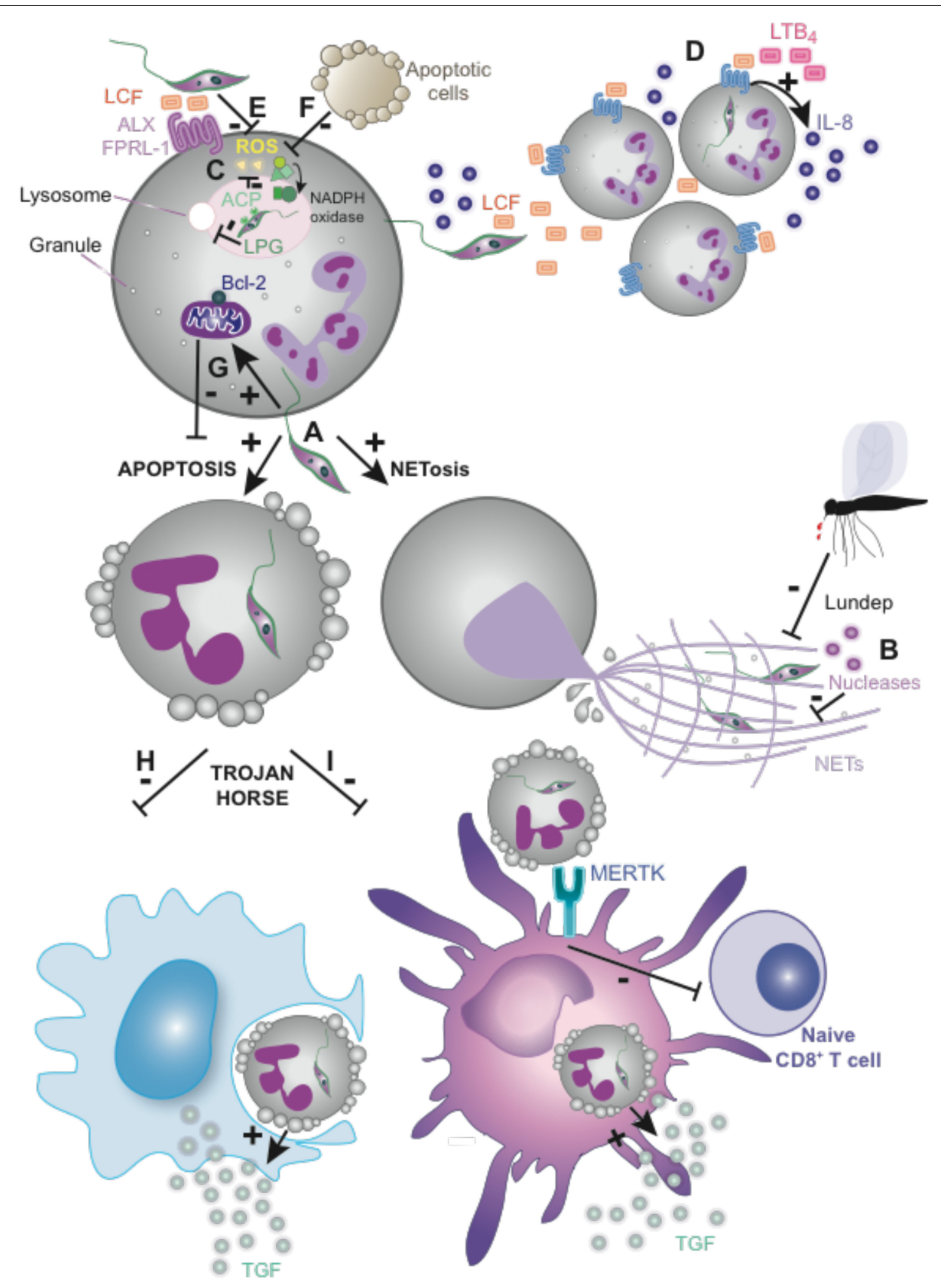

FIGURE 1 | Some Leishmania species evade neutrophils and target them for silent transmission. (A) L. major and L. amazonensis promastigotes induce apoptosis and/or NETosis in neutrophils. (B) NET-mediated killing inhibition by $L$. infantum and $L$. major nucleases and vector's endonuclease (Lundep). (C) LPG from $L$. donovani or $L$. major contributes to evade phagosome maturation while ACP and LCF from L. donovani inhibit the respiratory burst. (D) Recruitment of neutrophils to the site of the infection is mediated by LTB4 and might be induced by LCF from several Leishmania species, including $L$. major, $L$. donovani, and L. aethiopica. (E) LCF from the mentioned species inhibits the oxidative burst via the LXA receptor (ALX/FPRL-1) in vitro. (F) Apoptotic cell-mediated ROS downregulation promoting L. major survival. (G) L. major extends neutrophils lifespan by induction of anti-apoptotic protein Bcl-2 within other mechanisms (see the main text for more detailed information). (H,I) Silent transmission of Leishmania or "Trojan Horse" hypothesis. (H) Phagocytosis of apoptotic neutrophils containing intact parasites promotes an anti-inflammatory response by macrophages. (I) The engagement of MERTK on DCs by infected apoptotic neutrophils, upon infection with L. major Friedlin V1 strain, inhibits CD8 ${ }^{+}$T-cell priming. LPG, lipophosphoglycan; ACP, tartrate-resistant acid phosphatase; LCF, Leishmania chemotactic factor; $\mathrm{LTB}_{4}$, leukotriene B4; LXA

(Dermine et al., 2000). Moreover, L. donovani LPG promotes the accumulation of periphagosomal F-actin (Holm et al., 2001) (Winberg et al., 2009), avoiding in this manner the phagosome acidification and favoring the parasite intracellular survival (Figure 2B). The L. donovani metalloprotease GP63 (a surface and secreted glycoprotein of $63 \mathrm{kDa}$ ) downregulates 


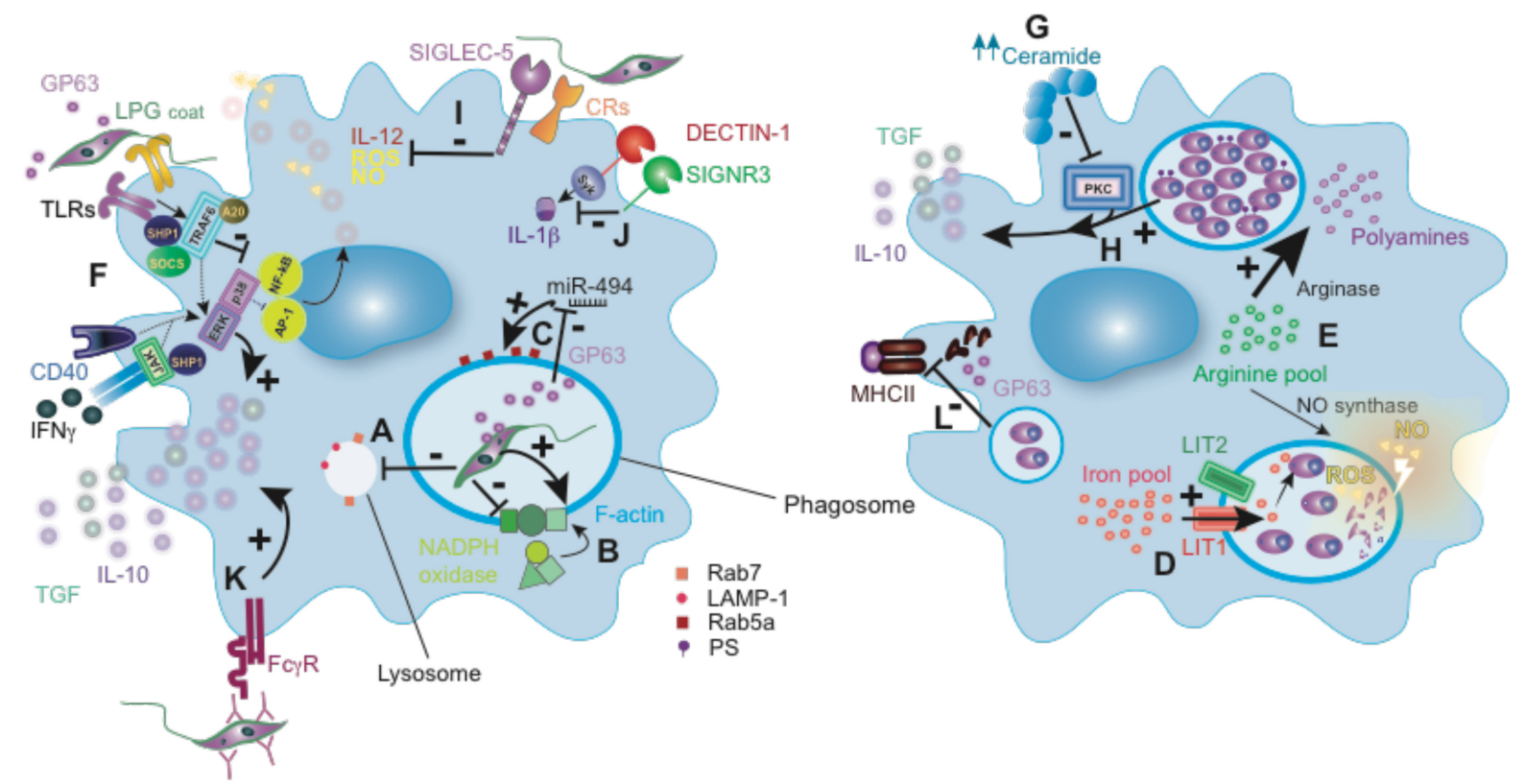

FIGURE 2 | Leishmania subversion of macrophage-mediated killing. (A) Delayed phagosome maturation by affecting the expression of late endosomal markers LAMP-1 and Rab7, as occurred with L. donovani (B) LPG from L. donovani mediates F-actin accumulation and LPG from L. donovani or L. major prevents NADPH oxidase complex assembly in the phagosome. (C) L. donovani metalloprotease GP63 modulation of phagosome Rab5a expression. (D) L. amazonensis-mediated host iron pool manipulation. (E) Some Leishmania species (detailed in the main text) mediate arginase upregulation to favor polyamines synthesis and parasite survival. (F) JAK/MAPK signaling inhibition by SOCs, SHP1 and A20 described for some Leishmania species, including L. major, L. donovani, L. mexicana and $L$. amazonensis. (G) PKC inhibition by $L$. donovani amastigotes-mediated ceramide overexpression. (H) PS expression by $L$. amazonensis amastigotes favors the production of anti-inflammatory cytokines. (I) $L$. donovani uses Siglec- 5 and $L$. major some CRs to silence the macrophages pro-inflammatory response.

(J) L. infantum SIGNR3 interaction inhibits Dectin-1 mediated IL-1 $\beta$ production. (K) Opsonized-L. major parasites recognition by Fc $\gamma R$ promotes anti-inflammatory cytokines. (L) MHC-II degradation by GP63 from L. amazonensis and L. donovani amastigotes. Rab7, Ras-related protein 7; LAMP-1, lysosomal-associated membrane protein 1; LPG, lipophosphoglycan; Rab5a, Ras-related protein 5A; GP63, glycoprotein 63; LIT1, Leishmania iron transporter 1; LIT2, Leishmania iron transporter 2; ROS, reactive oxygen species; NO, nitric oxide; TLRs, Toll-like receptors; SHP1, Src homology region 2 domain-containing phosphatase-1; SOCS, suppressors of cytokine signaling; A20, tumor necrosis factor alpha-induced protein 3; PS, phosphatidylserine; CRs, complement receptors; FcyR, Fc $\gamma$ receptor.

miR-494, which induces Rab5a expression in the phagosome to prevent lysosome fusion (Figure 2C) (Verma et al., 2017). Moreover, the cysteine peptidase B from L. mexicana regulates GP63 expression, thus indirectly influencing phagosome formation (Casgrain et al., 2016). Leishmania can also exploit host sphingolipids and lipid droplets as energy source and to neutralize the acidic environment inside the phagolysosome (Ali et al., 2012; Rabhi et al., 2016).

To proliferate intracellularly, Leishmania amastigotes require iron and arginine-derived polyamines, essential nutrients for their survival within the macrophage phagolysosome (Iniesta et al., 2001; Huynh and Andrews, 2008). L. amazonensis compensates the host iron efflux pump by the activation of its own iron transporters, LIT1 and LIT2, providing their mitochondria with iron to generate ROS and regulate the differentiation of virulent Leishmania amastigotes (Figure 2D) (Huynh et al., 2006; Mittra et al., 2013; Mittra et al., 2016; Mittra et al., 2017). During infection, the macrophage arginine pool is utilized to produce metabolites (NO and polyamines) for the host defense and its suppression, respectively. Leishmania infection up-regulates arginase activity in host macrophages, which favors polyamine synthesis and subverts NO synthase-dependent killing by competing for arginine (Gaur et al., 2007; Reguera et al., 2009;
Rogers et al., 2009; Badirzadeh et al., 2017). In fact, the arginase encoded by the parasite can influence macrophage responses (Boitz et al., 2017). Polyamines contribute to proliferation and to the synthesis of anti-oxidants, such as trypanothione, which neutralize ROS and enable L. donovani amastigote survival inside macrophage phagolysosomes (Figure 2E) (Colotti and Ilari, 2011; Goldman-Pinkovich et al., 2016). However, this mechanism seems to be not essential for the survival of $L$. donovani amastigotes (Boitz et al., 2017), but it is relevant during the promastigote stage.

\section{Modulating Macrophage Microbicide Response}

Once inside the macrophage, Leishmania modulates the pattern of cytokine secretion and inhibits the generation of $\mathrm{NO}$ and ROS to increase its survival inside the host. L. major promastigotes inhibit IL-12 while promoting IL-10 and TGF$\beta$ production from infected host macrophages (Figure 2F) (Reiner et al., 1994; Carrera et al., 1996). Most of these immunosuppressive actions depend on Leishmania-mediated host protein tyrosine phosphatases (PTPs) or phosphatidyl inositol-3 kinase (PI3K) recruitment, which leads to inhibition of JAK/STAT or MAPK signaling pathways, thus transforming 
macrophages to anti-inflammatory state as described for L. donovani and L. amazonensis (Nandan and Reiner, 1995; Blanchette et al., 1999; Nandan et al., 1999; Forget et al., 2006; Ruhland and Kima, 2009; Calegari-Silva et al., 2015).

Toll-like receptors (TLRs) expressed on innate immune cells are critical for Leishmania recognition, which determines the outcome of the infection (Faria et al., 2012). As a strategy to modulate the TLR response, depending on the species, Leishmania recruits suppressors of the cytokine signaling family proteins, SOCS-1 and SOCS-3, activates host de-ubiquitinating enzyme A20 or the Src homology 2 domain phosphotyrosine phosphatase 1 (SHP-1) (Figure 2F) (de Veer et al., 2003; Lapara and Kelly, 2010; Shweash et al., 2011; Srivastav et al., 2012, 2015). Moreover, L. donovani suppresses p38 phosphorylation while activates ERK1/2, resulting in inhibition of TLR2 and TLR4stimulated IL-12 and increase in IL-10 production (Chandra and Naik, 2008). Similarly, the activation of the ERK and MAPK pathway in response to IgG-opsonized L. amazonensis boosts IL-10 production (Yang et al., 2007). Several virulence factors derived from the parasite have been implicated in this process; LPG inhibits protein kinase C (Descoteaux and Turco, 1999), and stimulates ERK (Severn et al., 1992; Proudfoot et al., 1996; Feng et al., 1999; Prive and Descoteaux, 2000; DelgadoDominguez et al., 2010), favoring downregulation of iNOS and IL-12 production. L. donovani amastigotes similarly inhibit IL12 production despite lacking LPG on their surface, indicating that other parasite-derived molecules are involved in PKC activity inhibition (Olivier et al., 1992). For example, altering macrophage intracellular ceramide homeostasis by $L$. donovani results in impaired PKC signaling (Figure 2G) (Ghosh et al., 2001).

Similar to other Leishmania factors, like the elongation factor-1alpha (EF-1alpha) and fructose-1,6-bisphosphate aldolase described in L. donovani (Nandan et al., 2002, 2007), L. major GP63 can also promote the activation and recruitment of host PTPs, like SHP-1, which suppresses several kinase pathways, inhibiting several microbicidal macrophage functions (Gomez et al., 2009) (Figure 2F). Moreover, GP63 can inhibit macrophages inflammatory response through mTOR signaling pathway, which regulates the IL-12/IL-10 axis (Jaramillo et al., 2011; Cheekatla et al., 2012). GP63 also mediates proteolysis of some macrophage transcriptions factors, like AP-1 and NF- $\kappa$ B, and adaptor molecules, such as Dok family proteins (Gregory et al., 2008; Contreras et al., 2010; Alvarez de Celis et al., 2015). Using the same mechanism, GP63 also modulates protein tyrosine kinases and PKC activity (Chawla and Vishwakarma, 2003; Halle et al., 2009). In addition, the L. mexicana cysteine peptidase B promotes SHP-1 function in the macrophage, inhibiting NF- $\kappa \mathrm{B}$ signaling and consequently IL-12 and NO production (Cameron et al., 2004; Abu-Dayyeh et al., 2008, 2010). In addition, the glycosylphosphatidylinositol structure common for different Leishmania surface molecules (including LPG and GP63) inhibits TNF expression and dampens macrophage response to infection (Tachado et al., 1997). The kinetoplastid membrane protein-11 is another pathogenicity factor expressed in different Leishmania spp., including L. amazonensis amastigote stage (Matos et al., 2010) that increases IL-10 production and arginase activity while reduces NO production by macrophages
(Lacerda et al., 2012). At this stage, L. amazonensis amastigotes can expose phosphatidylserine analogs, promoting TGF- $\beta$ and IL-10 and inhibiting NO synthesis (Figure 2H) (Wanderley et al., 2006).

Leishmania can also target macrophage membrane-bound receptors to subvert the inflammatory response. Sialic acids in the parasite surface bind to Siglecs receptors on macrophages to dampen the immune response. Sialic acids recognition by Siglec-5 reduces levels of ROS, NO generation and promotes a Th2-prone cytokine response to $L$. donovani (Figure 2I) (Roy and Mandal, 2016). The C-type lectin receptor (CLR) SIGNR3 is targeted by L. infantum to inhibit Dectin-1-mediated IL-1 $\beta$ secretion, favoring parasite survival (Figure 2J) (Lefevre et al., 2013). Mannose receptor (MR) expressed by dermal macrophages is targeted by a non-healing strain of $L$. major. These cells are permissive for parasite grow even in a Th1immune environment, affecting the severity of cutaneous disease (Lee et al., 2018). In addition, the engagement of complement receptors (CRs) type 1 and type 3 by L. major inhibits respiratory burst and IL-12 production (Da Silva et al., 1989; Ricardo-Carter et al., 2013) (Figure 2I). Moreover, the engagement of the Fc receptor $(\mathrm{Fc} \gamma \mathrm{R})$ by opsonized-parasites promotes IL-10 and TGF- $\beta$ production by L. major infected macrophages (Figure $2 \mathbf{K}$ ) (Padigel and Farrell, 2005). L. amazonensis and L. major can also induce the expression of CD200 in macrophages, mediating iNOS inhibition and promoting the virulence of the parasites (Cortez et al., 2011). Additional mechanisms like secretion of exosomes or microRNA-mediated post-transcriptional regulation of inflammatory immune response genes have been described for L. donovani and L. amazonensis, which can modulate cytokine and NO generation by macrophages (Silverman et al., 2010; Muxel et al., 2017; Tiwari et al., 2017).

\section{Modulating Macrophage Antigen Presentation and Costimulatory Signals}

Another way used by Leishmania to perpetuate its presence inside the host is suppressing $\mathrm{T}$ cell-mediated immune responses by inhibiting presentation of Leishmania antigens in major histocompatibility complex (MHC) and dampening costimulatory signals provided by macrophages. Infection of macrophages affects their membrane lipid rafts fluidity and the disposition of MHC class II (MHC-II) molecules, leading to defective antigen presentation and $\mathrm{T}$ cell priming (Courret et al., 1999; Chakraborty et al., 2005; Roy et al., 2016). In addition, cysteine proteases from L. amazonensis and L. donovani amastigotes contribute to this process by degrading MHC-II molecules (Figure 2L) (De Souza Leao et al., 1995; Antoine et al., 1999). L. donovani-infected macrophages exhibit decreased expression of the co-stimulatory molecule B7-1 (Saha et al., 1995).

\section{Increasing Macrophage Survival}

Leishmania has evolved several mechanisms to extend the survival of the infected macrophages. Programmed death-1 receptor (PD-1), which mediates T-cell exhaustion, is negatively modulated by $L$. donovani to avoid macrophage apoptosis (Roy et al., 2017). In addition, L. donovani triggers AKT 
activation of the anti-apoptotic $\beta$-catenin, inhibiting the proapoptotic transcriptional regulator FOXO-1 (Gupta et al., 2016). L. donovani also prevents mitochondria-dependent apoptosis by inducing anti-apoptotic protein MCL-1 (Giri et al., 2016). Some factors encoded by the parasite, like the orthologs of the cytokine macrophage migration inhibitory factor (MIF), are involved in blocking macrophage apoptosis and prevent clearance of internalized parasites upon L. major infection (Holowka et al., 2016).

\section{DENDRITIC CELLS COMMANDING IMMUNITY AGAINST Leishmania}

Dendritic cells play a unique role in the immune system as antigen presenting cells that promote and sustain adaptive immunity while contribute at the same time to the induction of tolerance to self-antigens. DCs uptake and process Leishmania parasites or their antigens and subsequently migrate to lymph nodes (LNs) to prime $\mathrm{T}$ cells. Leishmania sensing by DCs triggers IL-12p70 production in both human and mouse DCs, a key cytokine to prime and maintain Th1 responses that ultimately lead to the control of the parasite (Gorak et al., 1998; von Stebut et al., 1998; Marovich et al., 2000; Leon et al., 2007). In order to escape, Leishmania parasites target DC activation either being silent or even inhibiting DC activation, motility and migration to draining LNs (Ponte-Sucre et al., 2001; Jebbari et al., 2002; De Trez et al., 2004; Revest et al., 2008; Sanabria et al., 2008; Figueiredo et al., 2012; Hermida et al., 2014; Iborra et al., 2016; von Stebut, 2017). DC-Leishmania interaction can vary depending on the different DC subset involved, as they are equipped with different pattern recognition receptors. In addition, several Leishmania species and different strains might be endowed with different pathogen associated molecular patterns and/or immune evasion strategies. Moreover, the interaction of the parasite and DCs can be direct or indirect, through other infected cells, and even the sandfly saliva may also modulate DCs function.

L. major inoculation induces a huge infiltration of neutrophils that phagocytose the majority of parasites but fails to kill them, although this is not the case for other Leishmania species (Regli et al., 2017). DCs reaching the inflammation site would thus mainly encounter apoptotic neutrophils harboring intracellular parasites. The capture of infected neutrophils by DCs in the skin acts as a key mechanism to inhibit their functions, delaying the development of adaptive immunity (Figures 1I, 3A) (RibeiroGomes et al., 2012). In fact, treatment of mice with two neutrophil-depleting antibodies, the GR-1-specific antibody RB68C5, which recognizes an epitope shared by Ly6G and Ly6C, and the Ly6G-specific antibody, 1A8, just before infection augments DCs maturation in the skin and the priming of $L$. major specific $\mathrm{CD}^{+} \mathrm{T}$ cells in vivo, which correlates with faster parasite clearance (Peters et al., 2008; Ribeiro-Gomes et al., 2012). Moreover, uptake of infected neutrophils inhibits DC maturation and their subsequent function as cross-priming $\mathrm{DC}$ in vivo (Ribeiro-Gomes et al., 2015). Upon L. major infection (Friedlin strain FV1), the engagement of the receptor tyrosine kinase Mer
(MERTK) on the DCs phagocytosing apoptotic neutrophils led to the impaired capacity for $\mathrm{CD} 8^{+} \mathrm{T}$-cell priming in vitro. MERTK acted as a tolerogenic receptor in resting macrophages and in the absence of inflammation (Figures 1I, 3A) (Zagorska et al., 2014). Interestingly, the related protozoan parasite Toxoplasma gondii does not elicit this inhibitory response to the same extent (Ribeiro-Gomes et al., 2015). In addition, the parasites co-evolved a strategy where the virulent inoculum comprises viable and dying promastigotes, which expose phospholipids analogs to phosphatidylserine (Weingartner et al., 2012), a prototypical apoptotic eat-me signal promoting phagocytosis in a "silent" way. Thus, DCs can also engulf free extracellular Leishmania promastigotes (Ng et al., 2008).

\section{Leishmania Modulates DC Maturation and Migration}

Upon recognition of pathogen-derived molecules, DCs migrate to lymphoid tissues and undergo a process of "maturation" that enhances antigen processing and presentation, expression of costimulatory molecules and cytokine secretion, governing the fate of adaptive immunity. Several in vivo studies demonstrate the importance of fully activated migratory DCs (CD86 ${ }^{\text {high }}$, $\mathrm{CD} 40^{\text {high }}, \mathrm{CCR}^{+}$, and $\mathrm{IL}-12^{+}$) in activation of $\mathrm{NK}$ cells and in the generation of protective Th1 responses against Leishmania parasites (Soong, 2008). Therefore, incomplete and delayed DC maturation could favor the establishment and amplification of Leishmania infection before the onset of immune responses. Of note, in an experimental model mimicking natural infection (low number L. major metacyclic promastigotes challenged in the ear dermis) a silent phase was observed with parasite replication in the absence of an inflammatory response. In this model, IL- $12^{+}$DCs were not detected until week 4 post-infection, peaking at week 6 and preceding full development of T cell-associated IFN- $\gamma$ release (Belkaid et al., 2000). L. major internalization by DCs is facilitated by IgG via Fc $\gamma$ RI and Fc $\gamma$ RIII, and engagement of these receptors is required for development of Th1 dependent immunity (Figure 3B) (Woelbing et al., 2006). However, it is unknown when B-cell priming against Leishmania occurs, and whether natural IgGs can opsonize Leishmania and promote DC engulfment. The existence of a "silent phase" suggests that Leishmania is able to modulate DC maturation, motility or migration. In fact, upon in vitro infection with high doses of L. major promastigotes, DCs did not exhibit upregulation of MHC class I/II, costimulatory molecules, such as CD40, CD86, as well as release of proinflammatory cytokines (Figure 3C) (von Stebut et al., 1998). Similarly, the presence of live L. amazonensis parasites during human DC differentiation in vitro decreased CD80 expression and IL-6 secretion (Favali et al., 2007). Mouse bone marrow-derived DCs (BMDCs) infected with L. amazonensis, L. braziliensis, L. major, or L. infantum metacyclic promastigotes showed decreased MHC-II and CD86 expression, and exhibited an impaired ability to induce T-cell proliferation (Neves et al., 2010; Figueiredo et al., 2012). In addition, some L. infantum excreted/secreted proteins (LipESP) reduced the ability of human DCs to respond in vitro to LPS, inhibiting maturation and IL-12p70 production (Figure 3D) 


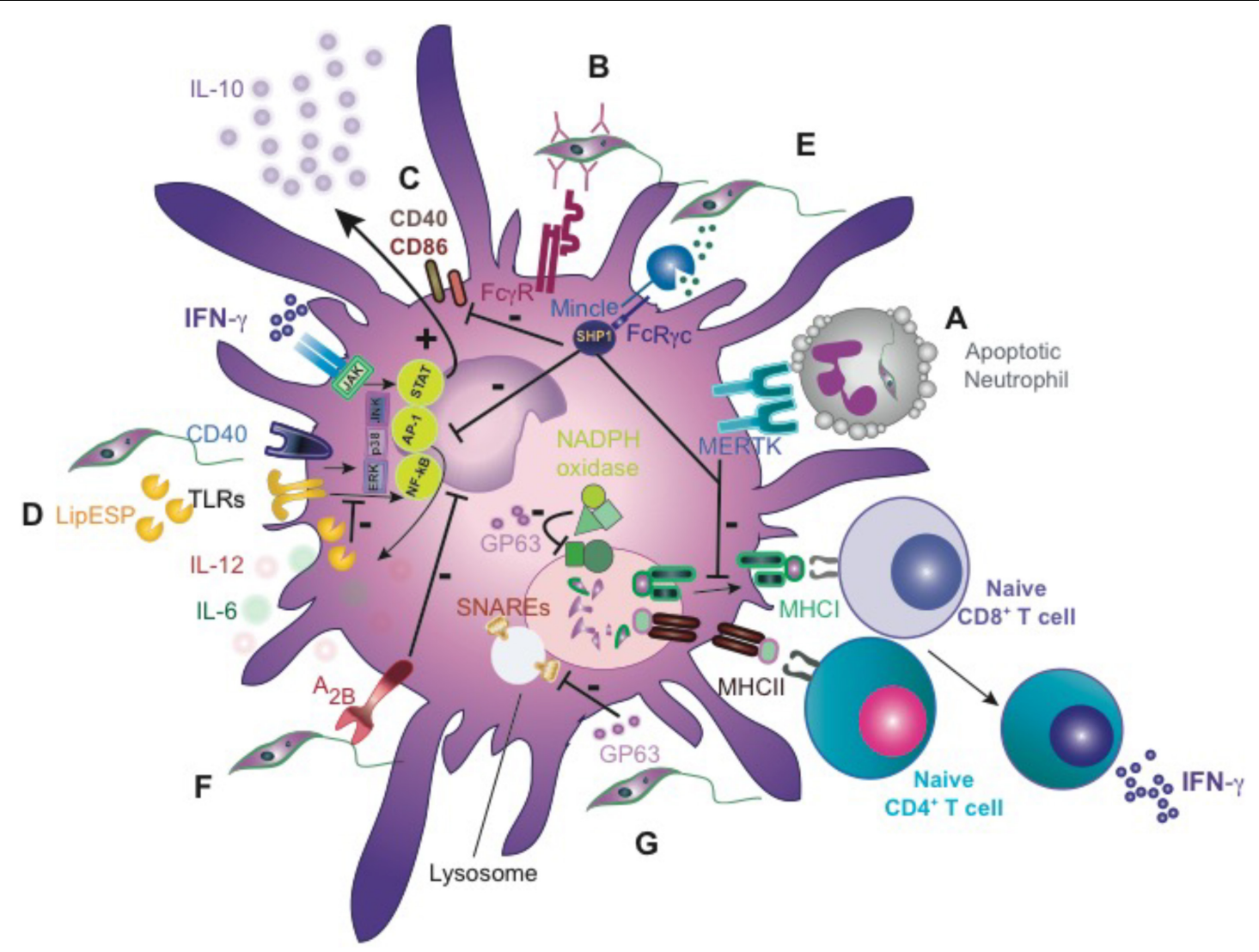

FIGURE 3 | Leishmania inhibits DC function. (A) Apoptotic cell clearance of L. major-infected neutrophils by DCs shuts down cross-priming of CD8 T cells in vitro by MERTK-dependent signaling. (B) Internalization of opsonized L. major by DCs via FcyR promotes DC activation and IL-12 production. (C) Downregulation of costimulatory molecules, CD40 and CD86 upon L. major infection in vitro. (D) L. infantum excreted/secreted factors (LipESP) reduce LPS- and CD40-mediated responses. (E) Binding of soluble Leishmania ligand(s) to Mincle promotes SHP-1 interaction and inhibitory signaling. (F) L. amazonensis exploits A(2B) receptor to inhibit DCs function. (G) GP63 cleaves SNAREs protein, preventing the assembly of the NADPH oxidase complex. FcyR, Fc $\gamma$ receptor; MERTK, tyrosine-protein kinase Mer; LipESP, L. infantum excreted/secreted proteins; A(2B) receptor, adenosine; GP63, glycoprotein 63; SNAREs, soluble NSF attachment protein receptor.

(Markikou-Ouni et al., 2015). Exosomes from L. donovani failed to prime monocyte-derived human DCs to drive the differentiation of naive CD4 T cells into IFN- $\gamma$-producing Th1 cells in vitro. Interestingly, vesicles from $L$. donovani deficient in HSP100, which exhibit a distinct protein cargo, have more proinflammatory phenotype in human DCs in vitro (Silverman et al., 2010).

The outcome of the DC interaction with the parasite depends on the Leishmania species and the developmental stage. DC maturation is not observed upon L. major promastigote infection, but can be induced by L. major amastigotes in vitro (von Stebut et al., 1998). In contrast, DCs infected with L. mexicana amastigotes do not show detectable levels of IL-12, or any other signs of activation (Bennett et al., 2001). Likewise, L. amazonensis amastigotes failed to induce CD40dependent IL-12 in vitro production in DCs (Figure 3D) (Qi et al., 2001; Boggiatto et al., 2009). Notably, DCs infected with L. amazonensis promastigotes displayed a "semi-activation" phenotype, produced relatively low levels of IL-12, and preferentially induced pathogenic $\mathrm{CD}^{+} \mathrm{T}$ cells (Xin et al., 2007). L. amazonensis amastigote-infected DCs were less mature and with lower antigen presenting capacity in vitro compared with promastigote-infected DCs (Xin et al., 2008). In contrast to parasite extract stimulation or infection, internalization of antibody-opsonized L. amazonensis promastigotes or amastigotes induces DC maturation, as shown by the overexpression of costimulatory, adhesion and MHC-II (Prina et al., 2004).

The mechanisms that Leishmania uses to sabotage DCs are still not fully defined. L. mexicana infection of the DC line DC2.4, inhibits the MAPK-signaling cascade, decreasing antigen-presentation capacity and IL-12 secretion (Figure 3D) (Contreras et al., 2014). This inhibition is mediated by the activation of PTPs. Leishmania can be detected by different PRRs, such as TLRs, CLRs and opsonizing antibodies via Fc receptors, which trigger activating and/or inhibitory signals (Woelbing et al., 2006; Lefevre et al., 2013). Mincle (Clec4e) mediates dampening of DC activation and migration following sensing of a ligand released by Leishmania (Iborra et al., 2016). Mincle couples to the Fc receptor $\gamma(\mathrm{FcR} \gamma)$ chain that bears immunoreceptor tyrosine-based activation motif (ITAM). Upon canonical signaling through Mincle, tyrosine residues in the FcR $\gamma$ 
chain are phosphorylated by Src-family kinases, followed by the recruitment and activation of the kinase Syk, which generates an activating signal that boosts inflammation (Sancho and Reis e Sousa, 2012, 2013). Notably, upon recognition of Leishmania ligand, Mincle shifts to an inhibitory ITAM configuration that recruits SHP-1 and dampens DC activation and migration induced by heterologous receptors sensing activating signals from Leishmania (Figure 3E) (Iborra et al., 2016). Thus, we observed a more robust IFN- $\gamma$-producing-CD4 ${ }^{+} \mathrm{T}$ cell response, milder dermal pathology and 10-fold reduction of the parasite burden compared to wild-type mice. Selective loss of SHP1 in $\mathrm{CD}_{11 \mathrm{c}^{+}}$cells phenocopies enhanced adaptive immunity to Leishmania (Iborra et al., 2016). Another way to dampen DC activation related to purinergic signaling has been demonstrated in DCs infected with L. amazonensis. Whereas extracellular ATP induces inflammation, adenosine is an important antiinflammatory mediator. In the presence of MRS1754, a highly selective $\mathrm{A}(2 \mathrm{~B})$ adenosine receptor antagonist, DCs exhibit an increased expression of MHC-II, CD86 and CD40, enhancing their ability to induce T-cell proliferation. In conclusion, $\mathrm{A}(2 \mathrm{~B})$ receptor activation may be used by Leishmania to inhibit DC function and evade the immune response (Figure 3F) (Figueiredo et al., 2012).

Leishmania may also subvert adaptive immunity by interfering with DC migration. In the steady state, dermal DCs are highly motile, continuously crawling through the interstitial space. Intradermal delivery of L. major immobilizes dermal DCs (Ng et al., 2008). Products secreted by $L$. major promastigotes inhibit the motility of DCs by up to $93 \%$, in a dosedependent and reversible manner (Jebbari et al., 2002). Coincubation with Leishmania in vitro, changes the migratory pattern of DCs when they are adoptively transferred to mice (Hermida et al., 2014). Similarly, we described that Leishmania inhibits DCs migration via Mincle (Iborra et al., 2016). DCs from mice with chronic $L$. donovani infection fail to migrate from the marginal zone to the periarteriolar region of the spleen. However, DCs eventually migrate and promote Th1 cell immunity and macrophage microbicidal activity (Leon et al., 2007).

Different DC subsets can coordinate the mounting of antiLeishmania response. L. major infection recruits monocytes to the dermis that generate Th1-promoting dermal monocytederived DCs (Leon et al., 2007). In addition, cDC1s (Batf3dependent DCs) are essential for the control of L. major (Ashok et al., 2014; Martinez-Lopez et al., 2015). Although this DC subset does not seem essential for Th1 or CTL priming (Martinez-Lopez et al., 2015), probably because $\mathrm{cDC} 1$ are resistant to infection (Henri et al., 2002), they excel in IL-12 production, which is crucial for maintenance of local Th1 immunity against L. major infection (Martinez-Lopez et al., 2015).

\section{Interfering With CD8 ${ }^{+}$T Cell Cross-Priming}

$\mathrm{CD} 8^{+} \mathrm{T}$ lymphocytes are components of the adaptive immune response that play an important role in protection against intracellular pathogens. The role of $\mathrm{CD} 8^{+} \mathrm{T}$ cells in the primary control of Leishmania is still controversial, given the different results obtained in different infection models. $\mathrm{CD}^{+} \mathrm{T}$ cells contribute to parasite control in visceral leishmaniasis (Stäger and Rafati, 2012), probably by recruiting inflammatory cells and maintaining granulomas. $\mathrm{CD} 8^{+} \mathrm{T}$ cells also contribute to parasite clearance against low doses of L. major (Belkaid et al., 2002b), where they also contribute to the cutaneous pathology associated to the infection, and even exacerbate disease (Novais and Scott, 2015). However, L. donovani induces defective antigen-specific $\mathrm{CD}^{+} \mathrm{T}$ cell responses, with a very limited clonal expansion (Joshi et al., 2009), compared with viral infections or following injection of irradiated Plasmodium (Sano et al., 2001). In fact, visceral leishmaniasis patients do not show $\mathrm{CD}^{+} \mathrm{T}$ cell effector responses (Gautam et al., 2014).

Limited and poor Leishmania antigen-processing and presentation into MHC Class I, could be one potential explanation. Processing of Leishmania antigens occurs in a TAP-independent, intraphagosomal pathway that is less efficient and requires higher amounts of secreted antigen than the endoplasmic reticulum-based, TAP-dependent crosspresentation pathway (Bertholet et al., 2006). In addition to other mechanisms discussed above, the major surface metalloprotease of Leishmania GP63 cleaves a subset of SNAREs, including VAMP8. The inactivation of VAMP8 prevents the assembly of the NADPH oxidase complex (NOX2), which is critical to limit the acidification in these cross-presentation compartments (Figure 3G) (Matheoud et al., 2013; Matte et al., 2016). The inhibition of acidification is critical to prevent the complete and premature destruction of MHC class I epitopes by the protease activity (Savina et al., 2006). As a consequence, the cross-presentation of Leishmania antigens on MHC class I molecules is actively inhibited by the parasite. $\mathrm{CD}^{+} \mathrm{T}$ cells undergo a second round of activation, become dysfunctional, and ultimately die from exhaustion during infection (Joshi et al., 2009). Given that high and constant antigenic stimulation causes $\mathrm{CD}^{+} \mathrm{T}$ cell "exhaustion" during chronic viral infections (Mueller and Ahmed, 2009), we could speculate that Leishmania antigens might be available for cross-presentation from other sources, like death infected macrophages.

\section{FIGHTING BACK IMMUNE EVASION BY VACCINATION}

Inoculation of live virulent $L$. major parasites causing autocuring cutaneous leishmaniasis lesions, a procedure known as leishmanization (Khamesipour et al., 2005) is the only efficient vaccine that induces immunity in human subjects (Saljoughian et al., 2014; Mendonca, 2016). Resistance to reinfection with $L$. major in mice has been linked to the induction of parasite persistence by $\mathrm{CD} 4{ }^{+} \mathrm{CD} 25^{+}$regulatory $\mathrm{T}$ cells secreting IL-10 (Belkaid et al., 2001, 2002a). The presence of small number of parasites in macrophages and DCs after primary challenge (Mandell and Beverley, 2017) preserves the concomitant immunity necessary to induce long-lasting defense (Sacks, 2014), consisting of migrating IFN- $\gamma$-producing effector $\mathrm{T}$ cells to the site of reinfection (Uzonna et al., 2001; Peters et al., 2014; Romano et al., 2015), and $\mathrm{CD}^{+}{ }^{+}$resident memory $\mathrm{T}$ cells 
in the infected skin (Glennie et al., 2015) that can further recruit effector $\mathrm{T}$ cells and inflammatory monocytes to the infected dermal site (Glennie et al., 2017).

Generation of long-lasting cellular immunity is the main objective of vaccines based on parasite proteins or extracts. Immunotherapy using DC-based vaccination is an emerging potent approach for harnessing the potential of a patient's own immune system to induce protection. DCs can be pulsed with parasite extracts alone (Ahuja et al., 1999; Carrion et al., 2008; Majumder et al., 2012; Masic et al., 2012), combined with adjuvants such as CpG-ODN (Carrion et al., 2008; Agallou et al., 2011, 2012; Majumder et al., 2012; Masic et al., 2012) or peptidoglycan (ligand of the TLR-2) (Jawed et al., 2016) or in DCs engineered to secrete IL-12 (Ahuja et al., 1999). These different treatments boost their immunogenicity in murine models (Ahuja et al., 1999; Majumder et al., 2012; Jawed et al., 2016), dampening IL-10 responses associated to parasite infection (Schwarz et al., 2013), and decreasing the tissue damage induced by the inflammatory response after infective challenge in vaccinated animals (Masic et al., 2012). Due to the high cost of these procedures, an alternative to the use of DCs primed with recombinant parasite proteins in humans will be to target Leishmania proteins to DCs by constructing recombinant chimeras, such as recombinant antibodies recognizing DCspecific receptors and containing leishmanial proteins. Using this strategy, antigen-specific $\mathrm{CD}^{+}{ }^{+} \mathrm{T}$ cells producing IFN- $\gamma, \mathrm{IL}-2$, and TNF were found in vaccinated mice (Matos et al., 2013).

\section{CONCLUDING REMARKS}

Myeloid cells, including neutrophils, monocytes, macrophages and DCs, orchestrate the generation of protective innate and adaptive immunity against Leishmania. Neutrophils are the first line of defense and generate an inflammatory response that restrains the parasite but, at the same time, and for some Leishmania species, neutrophils may act as carriers that facilitate silent infection of macrophages (Laskay et al., 2003, 2008; John and Hunter, 2008). Once within the macrophage, and depending on the Leishmania species, parasites delay phagosome formation and maturation, preventing phagosome acidification and action of proteases, while securing the nutrients needed for their survival. Moreover, the parasites modulate the pattern of cytokine secretion and inhibit the generation of NO and ROS, while

\section{REFERENCES}

Abu-Dayyeh, I., Hassani, K., Westra, E. R., Mottram, J. C., and Olivier, M. (2010). Comparative study of the ability of Leishmania mexicana promastigotes and amastigotes to alter macrophage signaling and functions. Infect. Immun. 78, 2438-2445. doi: 10.1128/IAI.00812-09

Abu-Dayyeh, I., Shio, M. T., Sato, S., Akira, S., Cousineau, B., and Olivier, M. (2008). Leishmania-induced IRAK-1 inactivation is mediated by SHP-1 interacting with an evolutionarily conserved KTIM motif. PLoS Negl. Trop. Dis. 2:e305. doi: 10.1371/journal.pntd. 0000305

Aga, E., Katschinski, D. M., van Zandbergen, G., Laufs, H., Hansen, B., Muller, K., et al. (2002). Inhibition of the spontaneous apoptosis of neutrophil granulocytes extending the survival of the infected macrophages. Similarly, L. major-infected neutrophils are silently phagocytozed by DCs in the skin and inhibit DC maturation and migration, delaying the development of adaptive immunity (Ribeiro-Gomes et al., 2012, 2015; Peters et al., 2014). Both monocyte-derived DCs and $\mathrm{CDC} 1 \mathrm{~s}$ are essential for the generation of Th1 immunity resulting in the control of L. major (Leon et al., 2007; Ashok et al., 2014; Martinez-Lopez et al., 2015). Leishmania acts at different levels to inhibit DCs, including dampening the MAPK pathway, decreasing antigen presentation capacity, IL12 secretion and migration, being this inhibition mediated by the activation of PTPs (Contreras et al., 2014; Iborra et al., 2016). Understanding which DC populations are key to trigger and achieve immunity to Leishmania and how parasites inhibit their activation and migration will help to improve a rational design of vaccines aimed to counteract parasite virulence factors, along with the use of the most adequate adjuvants.

\section{AUTHOR CONTRIBUTIONS}

MM-L, MS, SI, and DS conceived and wrote the manuscript. MM-L did the figures.

\section{FUNDING}

SI is funded by grant SAF2015-74561-JIN from the Spanish Ministry of Economy, Industry and Competitiveness (MINECO) and FEDER (European Fund for Regional Development). MM-L received a FPU fellowship (AP2010-5935) from the Spanish Ministry of Education. Work in the DS laboratory is funded by the CNIC and grant SAF2016-79040-R from MINECO, Agencia Estatal de Investigación and FEDER; B2017/BMD3733 Immunothercan-CM from Comunidad de Madrid; RD16/0015/0018-REEM from FIS-Instituto de Salud Carlos III, MINECO and FEDER; Acteria Foundation; Constantes y vitales prize (Atresmedia); La Marató de TV3 Foundation (201723); the European Commission (635122-PROCROP H2020) and the European Research Council (ERC-2016-Consolidator Grant 725091). The CNIC is supported by the MINECO and the ProCNIC Foundation, and is a Severo Ochoa Center of Excellence (MINECO award SEV-2015-0505).

by the intracellular parasite Leishmania major. J. Immunol. 169, 898-905. doi: 10.4049/jimmunol.169.2.898

Agallou, M., Margaroni, M., and Karagouni, E. (2011). Cellular vaccination with bone marrow-derived dendritic cells pulsed with a peptide of Leishmania infantum KMP-11 and CpG oligonucleotides induces protection in a murine model of visceral leishmaniasis. Vaccine 29, 5053-5064. doi: 10.1016/j.vaccine. 2011.04.089

Agallou, M., Smirlis, D., Soteriadou, K. P., and Karagouni, E. (2012). Vaccination with Leishmania histone $\mathrm{H} 1$-pulsed dendritic cells confers protection in murine visceral leishmaniasis. Vaccine 30, 5086-5093. doi: 10.1016/j.vaccine.2012. 05.075

Ahuja, S. S., Reddick, R. L., Sato, N., Montalbo, E., Kostecki, V., Zhao, W., et al. (1999). Dendritic cell (DC)-based anti-infective strategies: DCs engineered 
to secrete IL-12 are a potent vaccine in a murine model of an intracellular infection. J. Immunol. 163, 3890-3897.

Akhoundi, M., Kuhls, K., Cannet, A., Votypka, J., Marty, P., Delaunay, P., et al. (2016). A historical overview of the classification. Evolution, and dispersion of Leishmania parasites and sandflies. PLoS Negl. Trop. Dis. 10:e0004349. doi: 10.1371/journal.pntd.0004349

Ali, H. Z., Harding, C. R., and Denny, P. W. (2012). Endocytosis and sphingolipid scavenging in Leishmania mexicana amastigotes. Biochem. Res. Int. 2012:691363. doi: 10.1155/2012/691363

Alvarez de Celis, H., Gomez, C. P., Descoteaux, A., and Duplay, P. (2015). Dok proteins are recruited to the phagosome and degraded in a GP63-dependent manner during Leishmania major infection. Microbes Infect. 17, 285-294. doi: 10.1016/j.micinf.2014.12.011

Al Tuwaijri, A. S., Al Mofleh, I. A., and Mahmoud, A. A. (1990). Effect of Leishmania major on human polymorphonuclear leucocyte function in vitro. J. Med. Microbiol. 32, 189-193. doi: 10.1099/00222615-32-3-189

Antoine, J. C., Lang, T., Prina, E., Courret, N., and Hellio, R. (1999). H-2M molecules, like MHC class II molecules, are targeted to parasitophorous vacuoles of Leishmania-infected macrophages and internalized by amastigotes of L. amazonensis and L. mexicana. J. Cell Sci. 112 (Pt 15), 2559-2570.

Ashok, D., Schuster, S., Ronet, C., Rosa, M., Mack, V., Lavanchy, C., et al. (2014). Cross-presenting dendritic cells are required for control of Leishmania major infection. Eur. J. Immunol. 44, 1422-1432. doi: 10.1002/eji.201344242

Badirzadeh, A., Taheri, T., Taslimi, Y., Abdossamadi, Z., Heidari-Kharaji, M., Gholami, E., et al. (2017). Arginase activity in pathogenic and non-pathogenic species of Leishmania parasites. PLoS Negl. Trop. Dis. 11:e0005774. doi: 10.1371/ journal.pntd.0005774

Bajenoff, M., Breart, B., Huang, A. Y., Qi, H., Cazareth, J., Braud, V. M., et al. (2006). Natural killer cell behavior in lymph nodes revealed by static and real-time imaging. J. Exp. Med. 203, 619-631. doi: 10.1084/jem.20051474

Barrientos, L., Bignon, A., Gueguen, C., de Chaisemartin, L., Gorges, R., Sandre, C., et al. (2014). Neutrophil extracellular traps downregulate lipopolysaccharideinduced activation of monocyte-derived dendritic cells. J. Immunol. 193, 5689-5698. doi: 10.4049/jimmunol.1400586

Belkaid, Y., Hoffmann, K. F., Mendez, S., Kamhawi, S., Udey, M. C., Wynn, T. A., et al. (2001). The role of interleukin (IL)-10 in the persistence of Leishmania major in the skin after healing and the therapeutic potential of anti-IL-10 receptor antibody for sterile cure. J. Exp. Med. 194, 1497-1506. doi: 10.1084/ jem.194.10.1497

Belkaid, Y., Mendez, S., Lira, R., Kadambi, N., Milon, G., and Sacks, D. (2000). A natural model of Leishmania major infection reveals a prolonged "silent" phase of parasite amplification in the skin before the onset of lesion formation and immunity. J. Immunol. 165, 969-977. doi: 10.4049/jimmunol.165. 2.969

Belkaid, Y., Piccirillo, C. A., Mendez, S., Shevach, E. M., and Sacks, D. L. (2002a). CD4+CD25+ regulatory $\mathrm{T}$ cells control Leishmania major persistence and immunity. Nature 420, 502-507. doi: 10.1038/nature01152

Belkaid, Y., von Stebut, E., Mendez, S., Lira, R., Caler, E., Bertholet, S., et al. (2002b). CD8 + T cells are required for primary immunity in C57BL/6 mice following low-dose, intradermal challenge with Leishmania major. J. Immunol. 168, 3992-4000.

Bennett, C. L., Misslitz, A., Colledge, L., Aebischer, T., and Blackburn, C. C. (2001). Silent infection of bone marrow-derived dendritic cells by Leishmania mexicana amastigotes. Eur. J. Immunol. 31, 876-883. doi: 10.1002/1521-4141(200103)31: 3<876::AID-IMMU876>3.0.CO;2-I

Bertholet, S., Goldszmid, R., Morrot, A., Debrabant, A., Afrin, F., CollazoCustodio, C., et al. (2006). Leishmania antigens are presented to CD8+ T cells by a transporter associated with antigen processing-independent pathway in vitro and in vivo. J. Immunol. 177, 3525-3533. doi: 10.4049/jimmunol.177.6. 3525

Blanchette, J., Racette, N., Faure, R., Siminovitch, K. A., and Olivier, M. (1999). Leishmania-induced increases in activation of macrophage SHP1 tyrosine phosphatase are associated with impaired IFN-gamma-triggered JAK2 activation. Eur. J. Immunol. 29, 3737-3744. doi: 10.1002/(SICI)15214141(199911)29:11<3737::AID-IMMU3737>3.0.CO;2-S

Bogdan, C., Moll, H., Solbach, W., and Rollinghoff, M. (1990). Tumor necrosis factor-alpha in combination with interferon-gamma, but not with interleukin 4 activates murine macrophages for elimination of Leishmania major amastigotes. Eur. J. Immunol. 20, 1131-1135. doi: 10.1002/eji.18302 00528

Boggiatto, P. M., Jie, F., Ghosh, M., Gibson-Corley, K. N., Ramer-Tait, A. E., Jones, D. E., et al. (2009). Altered dendritic cell phenotype in response to Leishmania amazonensis amastigote infection is mediated by MAP kinase, ERK. Am. J. Pathol. 174, 1818-1826. doi: 10.2353/ajpath.2009.080905

Boitz, J. M., Gilroy, C. A., Olenyik, T. D., Paradis, D., Perdeh, J., Dearman, K., et al. (2017). Arginase is essential for survival of Leishmania donovani promastigotes but not intracellular amastigotes. Infect. Immun. 85:e00554-16. doi: 10.1128/ IAI.00554- 16

Brinkmann, V., Reichard, U., Goosmann, C., and Fauler, B. (2004). Neutrophil extracellular traps kill bacteria. Science 303, 1532-1535. doi: 10.1126/science. 1092385

Bronte, V., and Zanovello, P. (2005). Regulation of immune responses by L-arginine metabolism. Nat. Rev. Immunol. 5, 641-654. doi: 10.1038/nri1668

Calegari-Silva, T. C., Vivarini, A. C., Miqueline, M., Dos Santos, G. R., Teixeira, K. L., Saliba, A. M., et al. (2015). The human parasite Leishmania amazonensis downregulates iNOS expression via NF-kappaB p50/p50 homodimer: role of the PI3K/Akt pathway. Open Biol. 5:150118. doi: 10.1098/rsob.150118

Cameron, P., McGachy, A., Anderson, M., Paul, A., Coombs, G. H., Mottram, J. C., et al. (2004). Inhibition of lipopolysaccharide-induced macrophage IL-12 production by Leishmania mexicana amastigotes: the role of cysteine peptidases and the NF-kappaB signaling pathway. J. Immunol. 173, 3297-3304. doi: 10. 4049/jimmunol.173.5.3297

Carlsen, E. D., Liang, Y., Shelite, T. R., Walker, D. H., Melby, P. C., and Soong, L. (2015). Permissive and protective roles for neutrophils in leishmaniasis. Clin. Exp. Immunol. 182, 109-118. doi: 10.1111/cei.12674

Carrera, L., Gazzinelli, R. T., Badolato, R., Hieny, S., Muller, W., Kuhn, R., et al. (1996). Leishmania promastigotes selectively inhibit interleukin 12 induction in bone marrow-derived macrophages from susceptible and resistant mice. J. Exp. Med. 183, 515-526. doi: 10.1084/jem.183.2.515

Carrion, J., Folgueira, C., and Alonso, C. (2008). Immunization strategies against visceral leishmaniosis with the nucleosomal histones of Leishmania infantum encoded in DNA vaccine or pulsed in dendritic cells. Vaccine 26, 2537-2544. doi: 10.1016/j.vaccine.2008.03.003

Casgrain, P. A., Martel, C., McMaster, W. R., Mottram, J. C., Olivier, M., and Descoteaux, A. (2016). Cysteine peptidase B regulates Leishmania mexicana virulence through the modulation of GP63 expression. PLoS Pathog. 12:e1005658. doi: 10.1371/journal.ppat.1005658

Chagas, A. C., Oliveira, F., Debrabant, A., Valenzuela, J. G., Ribeiro, J. M., and Calvo, E. (2014). Lundep, a sand fly salivary endonuclease increases Leishmania parasite survival in neutrophils and inhibits XIIa contact activation in human plasma. PLoS Pathog. 10:e1003923. doi: 10.1371/journal.ppat.1003923

Chakraborty, D., Banerjee, S., Sen, A., Banerjee, K. K., Das, P., and Roy, S. (2005). Leishmania donovani affects antigen presentation of macrophage by disrupting lipid rafts. J. Immunol. 175, 3214-3224. doi: 10.4049/jimmunol.175.5.3214

Chandra, D., and Naik, S. (2008). Leishmania donovani infection downregulates TLR2-stimulated IL-12p40 and activates IL-10 in cells of macrophage/monocytic lineage by modulating MAPK pathways through a contact-dependent mechanism. Clin. Exp. Immunol. 154, 224-234. doi: 10.1111/j.1365-2249.2008.03741.x

Charmoy, M., Auderset, F., Allenbach, C., and Tacchini-Cottier, F. (2010a). The prominent role of neutrophils during the initial phase of infection by Leishmania parasites. J. Biomed. Biotechnol. 2010:719361. doi: 10.1155/2010/ 719361

Charmoy, M., Brunner-Agten, S., Aebischer, D., Auderset, F., Launois, P., Milon, G., et al. (2010b). Neutrophil-derived CCL3 is essential for the rapid recruitment of dendritic cells to the site of Leishmania major inoculation in resistant mice. PLoS Pathog. 6:e1000755. doi: 10.1371/journal.ppat.10 00755

Chatelain, R., Varkila, K., and Coffman, R. L. (1992). IL-4 induces a Th2 response in Leishmania major-infected mice. J. Immunol. 148, 1182-1187.

Chawla, M., and Vishwakarma, R. A. (2003). Alkylacylglycerolipid domain of GPI molecules of Leishmania is responsible for inhibition of PKC-mediated c-fos expression. J. Lipid Res. 44, 594-600. doi: 10.1194/jlr.M200296-JLR200

Cheekatla, S. S., Aggarwal, A., and Naik, S. (2012). mTOR signaling pathway regulates the IL-12/IL-10 axis in Leishmania donovani infection. Med. Microbiol. Immunol. 201, 37-46. doi: 10.1007/s00430-011-0202-5 
Colmenares, M., Kima, P. E., Samoff, E., Soong, L., and McMahon-Pratt, D. (2003). Perforin and gamma interferon are critical CD8 + T-cell-mediated responses in vaccine-induced immunity against Leishmania amazonensis infection. Infect. Immun. 71, 3172-3182. doi: 10.1128/IAI.71.6.3172-3182.2003

Colotti, G., and Ilari, A. (2011). Polyamine metabolism in Leishmania: from arginine to trypanothione. Amino Acids 40, 269-285. doi: 10.1007/s00726-0100630-3

Colpitts, S. L., Dalton, N. M., and Scott, P. (2009). IL-7 receptor expression provides the potential for long-term survival of both CD62Lhigh central memory $\mathrm{T}$ cells and Th1 effector cells during Leishmania major infection. J. Immunol. 182, 5702-5711. doi: 10.4049/jimmunol.0803450

Contreras, I., Estrada, J. A., Guak, H., Martel, C., Borjian, A., Ralph, B., et al. (2014). Impact of Leishmania mexicana infection on dendritic cell signaling and functions. PLoS Negl. Trop. Dis. 8:e3202. doi: 10.1371/journal.pntd.0003202

Contreras, I., Gomez, M. A., Nguyen, O., Shio, M. T., McMaster, R. W., and Olivier, M. (2010). Leishmania-induced inactivation of the macrophage transcription factor AP-1 is mediated by the parasite metalloprotease GP63. PLoS Pathog. 6:e1001148. doi: 10.1371/journal.ppat.1001148

Cortez, M., Huynh, C., Fernandes, M. C., Kennedy, K. A., Aderem, A., and Andrews, N. W. (2011). Leishmania promotes its own virulence by inducing expression of the host immune inhibitory ligand CD200. Cell Host Microbe 9, 463-471. doi: 10.1016/j.chom.2011.04.014

Courret, N., Prina, E., Mougneau, E., Saraiva, E. M., Sacks, D. L., Glaichenhaus, N., et al. (1999). Presentation of the Leishmania antigen LACK by infected macrophages is dependent upon the virulence of the phagocytosed parasites. Eur. J. Immunol. 29, 762-773. doi: 10.1002/(SICI)1521-4141(199903)29: $03<762:: A I D-I M M U 762>3.0 . C O ; 2-4$

Da Silva, R. P., Hall, B. F., Joiner, K. A., and Sacks, D. L. (1989). CR1, the $\mathrm{C} 3 \mathrm{~b}$ receptor, mediates binding of infective Leishmania major metacyclic promastigotes to human macrophages. J. Immunol. 143, 617-622.

de Menezes, J. P., Saraiva, E. M., and da Rocha-Azevedo, B. (2016). The site of the bite: Leishmania interaction with macrophages, neutrophils and the extracellular matrix in the dermis. Parasit Vectors 9:264. doi: 10.1186/s13071016-1540-3

De Souza Leao, S., Lang, T., Prina, E., Hellio, R., and Antoine, J. C. (1995). Intracellular Leishmania amazonensis amastigotes internalize and degrade MHC class II molecules of their host cells. J. Cell Sci. 108 (Pt 10), 3219-3231.

De Trez, C., Brait, M., Leo, O., Aebischer, T., Torrentera, F. A., Carlier, Y., et al. (2004). Myd88-dependent in vivo maturation of splenic dendritic cells induced by Leishmania donovani and other Leishmania species. Infect. Immun. 72, 824-832. doi: 10.1128/IAI.72.2.824-832.2004

de Veer, M. J., Curtis, J. M., Baldwin, T. M., DiDonato, J. A., Sexton, A., McConville, M. J., et al. (2003). MyD88 is essential for clearance of Leishmania major: possible role for lipophosphoglycan and Toll-like receptor 2 signaling. Eur. J. Immunol. 33, 2822-2831. doi: 10.1002/eji.200324128

Delgado-Dominguez, J., Gonzalez-Aguilar, H., Aguirre-Garcia, M., GutierrezKobeh, L., Berzunza-Cruz, M., Ruiz-Remigio, A., et al. (2010). Leishmania mexicana lipophosphoglycan differentially regulates PKCalpha-induced oxidative burst in macrophages of $\mathrm{BALB} / \mathrm{c}$ and $\mathrm{C} 57 \mathrm{BL} / 6$ mice. Parasite Immunol. 32, 440-449. doi: 10.1111/j.1365-3024.2010.01205.x

Dermine, J. F., Scianimanico, S., Prive, C., Descoteaux, A., and Desjardins, M. (2000). Leishmania promastigotes require lipophosphoglycan to actively modulate the fusion properties of phagosomes at an early step of phagocytosis. Cell Microbiol. 2, 115-126. doi: 10.1046/j.1462-5822.2000.00037.x

Descoteaux, A., and Turco, S. J. (1999). Glycoconjugates in Leishmania infectivity. Biochim. Biophys. Acta 1455, 341-352. doi: 10.1016/S0925-4439(99)00065-4

Desjardins, M., and Descoteaux, A. (1997). Inhibition of phagolysosomal biogenesis by the Leishmania lipophosphoglycan. J. Exp. Med. 185, 2061-2068. doi: $10.1084 /$ jem.185.12.2061

Faria, M. S., Reis, F. C., and Lima, A. P. (2012). Toll-like receptors in Leishmania infections: guardians or promoters? J. Parasitol. Res. 2012:930257. doi: 10.1155/ 2012/930257

Favali, C., Tavares, N., Clarencio, J., Barral, A., Barral-Netto, M., and Brodskyn, C. (2007). Leishmania amazonensis infection impairs differentiation and function of human dendritic cells. J. Leukoc. Biol. 82, 1401-1406. doi: 10.1189/jlb. 0307187

Feng, G. J., Goodridge, H. S., Harnett, M. M., Wei, X. Q., Nikolaev, A. V., Higson, A. P., et al. (1999). Extracellular signal-related kinase
(ERK) and p38 mitogen-activated protein (MAP) kinases differentially regulate the lipopolysaccharide-mediated induction of inducible nitric oxide synthase and IL-12 in macrophages: Leishmania phosphoglycans subvert macrophage IL-12 production by targeting ERK MAP kinase. J. Immunol. 163, 6403-6412.

Figueiredo, A. B., Serafim, T. D., Marques-da-Silva, E. A., Meyer-Fernandes, J. R., and Afonso, L. C. (2012). Leishmania amazonensis impairs DC function by inhibiting $\mathrm{CD} 40$ expression via $\mathrm{A} 2 \mathrm{~B}$ adenosine receptor activation. Eur. J. Immunol. 42, 1203-1215. doi: 10.1002/eji.201141926

Forget, G., Gregory, D. J., Whitcombe, L. A., and Olivier, M. (2006). Role of host protein tyrosine phosphatase SHP-1 in Leishmania donovani-induced inhibition of nitric oxide production. Infect. Immun. 74, 6272-6279. doi: 10. 1128/IAI.00853-05

Fuchs, T. A., Abed, U., Goosmann, C., Hurwitz, R., Schulze, I., Wahn, V., et al. (2007). Novel cell death program leads to neutrophil extracellular traps. J. Cell Biol. 176, 231-241. doi: 10.1083/jcb.200606027

Gabriel, C., McMaster, W. R., Girard, D., and Descoteaux, A. (2010). Leishmania donovani promastigotes evade the antimicrobial activity of neutrophil extracellular traps. J. Immunol. 185, 4319-4327. doi: 10.4049/jimmunol. 1000893

Gaur, U., Roberts, S. C., Dalvi, R. P., Corraliza, I., Ullman, B., and Wilson, M. E. (2007). An effect of parasite-encoded arginase on the outcome of murine cutaneous leishmaniasis. J. Immunol. 179, 8446-8453. doi: 10.4049/jimmunol. 179.12.8446

Gautam, S., Kumar, R., Singh, N., Singh, A. K., Rai, M., Sacks, D., et al. (2014). CD8 T cell exhaustion in human visceral leishmaniasis. J. Infect. Dis. 209, 290-299. doi: 10.1093/infdis/jit401

Geiger, A., Bossard, G., Sereno, D., Pissarra, J., Lemesre, J. L., Vincendeau, P., et al. (2016). Escaping deleterious immune response in their hosts: lessons from trypanosomatids. Front. Immunol. 7:212. doi: 10.3389/fimmu.2016.00212

Ghosh, S., Bhattacharyya, S., Das, S., Raha, S., Maulik, N., Das, D. K., et al. (2001). Generation of ceramide in murine macrophages infected with Leishmania donovani alters macrophage signaling events and aids intracellular parasitic survival. Mol. Cell. Biochem. 223, 47-60. doi: 10.1023/A:1017996609928

Giri, J., Srivastav, S., Basu, M., Palit, S., Gupta, P., and Ukil, A. (2016). Leishmania donovani exploits myeloid cell leukemia 1 (MCL-1) protein to prevent mitochondria-dependent host cell apoptosis. J. Biol. Chem. 291, 3496-3507. doi: 10.1074/jbc.M115.672873

Glennie, N. D., Volk, S. W., and Scott, P. (2017). Skin-resident CD4+ T cells protect against Leishmania major by recruiting and activating inflammatory monocytes. PLoS Pathog. 13:e1006349. doi: 10.1371/journal.ppat.1006349

Glennie, N. D., Yeramilli, V. A., Beiting, D. P., Volk, S. W., Weaver, C. T., and Scott, P. (2015). Skin-resident memory CD4+ T cells enhance protection against Leishmania major infection. J. Exp. Med. 212, 1405-1414. doi: 10.1084/ jem.20142101

Goldman-Pinkovich, A., Balno, C., Strasser, R., Zeituni-Molad, M., Bendelak, K., Rentsch, D., et al. (2016). An arginine deprivation response pathway is induced in Leishmania during macrophage invasion. PLoS Pathog. 12:e1005494. doi: 10.1371/journal.ppat.1005494

Gomez, M. A., Contreras, I., Halle, M., Tremblay, M. L., McMaster, R. W., and Olivier, M. (2009). Leishmania GP63 alters host signaling through cleavageactivated protein tyrosine phosphatases. Sci. Signal. 2:ra58. doi: 10.1126/ scisignal.2000213

Gorak, P. M., Engwerda, C. R., and Kaye, P. M. (1998). Dendritic cells, but not macrophages, produce IL-12 immediately following Leishmania donovani infection. Eur. J. Immunol. 28, 687-695. doi: 10.1002/(SICI)1521-4141(199802) 28:02<687::AID-IMMU687>3.0.CO;2-N

Gordon, S. (2003). Alternative activation of macrophages. Nat. Rev. Immunol. 3 , 23-35. doi: 10.1038/nri978

Green, S. J., Meltzer, M. S., Hibbs, J. B. Jr., and Nacy, C. A. (1990). Activated macrophages destroy intracellular Leishmania major amastigotes by an L-arginine-dependent killing mechanism. J. Immunol. 144, 278-283.

Gregory, D. J., Godbout, M., Contreras, I., Forget, G., and Olivier, M. (2008). A novel form of NF-kappaB is induced by Leishmania infection: involvement in macrophage gene expression. Eur. J. Immunol. 38, 1071-1081. doi: 10.1002/ eji.200737586

Gueirard, P., Laplante, A., Rondeau, C., Milon, G., and Desjardins, M. (2008). Trafficking of Leishmania donovani promastigotes in non-lytic compartments 
in neutrophils enables the subsequent transfer of parasites to macrophages. Cell Microbiol. 10, 100-111. doi: 10.1111/j.1462-5822.2007.01018.x

Guimaraes-Costa, A. B., DeSouza-Vieira, T. S., Paletta-Silva, R., FreitasMesquita, A. L., Meyer-Fernandes, J. R., and Saraiva, E. M. (2014). 3'-nucleotidase/nuclease activity allows Leishmania parasites to escape killing by neutrophil extracellular traps. Infect. Immun. 82, 1732-1740. doi: 10.1128/ IAI.01232-13

Guimaraes-Costa, A. B., Nascimento, M. T., Froment, G. S., Soares, R. P., Morgado, F. N., Conceicao-Silva, F., et al. (2009). Leishmania amazonensis promastigotes induce and are killed by neutrophil extracellular traps. Proc. Natl. Acad. Sci. U.S.A. 106, 6748-6753. doi: 10.1073/pnas.0900226106

Guimaraes-Costa, A. B., Rochael, N. C., Oliveira, F., Echevarria-Lima, J., and Saraiva, E. M. (2017). Neutrophil extracellular traps reprogram IL-4/GM-CSFinduced monocyte differentiation to anti-inflammatory macrophages. Front. Immunol. 8:523. doi: 10.3389/fimmu.2017.00523

Gupta, P., Srivastav, S., Saha, S., Das, P. K., and Ukil, A. (2016). Leishmania donovani inhibits macrophage apoptosis and pro-inflammatory response through AKT-mediated regulation of beta-catenin and FOXO-1. Cell Death Differ 23, 1815-1826. doi: 10.1038/cdd.2016.101

Gurunathan, S., Sacks, D. L., Brown, D. R., Reiner, S. L., Charest, H., Glaichenhaus, N., et al. (1997). Vaccination with DNA encoding the immunodominant LACK parasite antigen confers protective immunity to mice infected with Leishmania major. J. Exp. Med. 186, 1137-1147. doi: 10.1084/jem. 186.7.1137

Halle, M., Gomez, M. A., Stuible, M., Shimizu, H., McMaster, W. R., Olivier, M., et al. (2009). The Leishmania surface protease GP63 cleaves multiple intracellular proteins and actively participates in p38 mitogen-activated protein kinase inactivation. J. Biol. Chem. 284, 6893-6908. doi: 10.1074/jbc. M805861200

Heinzel, F. P., Sadick, M. D., Holaday, B. J., Coffman, R. L., and Locksley, R. M. (1989). Reciprocal expression of interferon gamma or interleukin 4 during the resolution or progression of murine leishmaniasis. Evidence for expansion of distinct helper T cell subsets. J. Exp. Med. 169, 59-72. doi: 10.1084/jem. 169.1 .59

Heinzel, F. P., Schoenhaut, D. S., Rerko, R. M., Rosser, L. E., and Gately, M. K. (1993). Recombinant interleukin 12 cures mice infected with Leishmania major. J. Exp. Med. 177, 1505-1509. doi: 10.1084/jem.177.5.1505

Henri, S., Curtis, J., Hochrein, H., Vremec, D., Shortman, K., and Handman, E. (2002). Hierarchy of susceptibility of dendritic cell subsets to infection by Leishmania major: inverse relationship to interleukin-12 production. Infect. Immun. 70, 3874-3880. doi: 10.1128/IAI.70.7.3874-3880.2002

Hermida, M. D., Doria, P. G., Taguchi, A. M., Mengel, J. O., and dos-Santos, W. (2014). Leishmania amazonensis infection impairs dendritic cell migration from the inflammatory site to the draining lymph node. BMC Infect. Dis. 14:450. doi: 10.1186/1471-2334-14-450

Holm, A., Tejle, K., Magnusson, K. E., Descoteaux, A., and Rasmusson, B. (2001). Leishmania donovani lipophosphoglycan causes periphagosomal actin accumulation: correlation with impaired translocation of PKCalpha and defective phagosome maturation. Cell Microbiol. 3, 439-447. doi: 10.1046/j. 1462-5822.2001.00127.x

Holowka, T., Castilho, T. M., Garcia, A. B., Sun, T., McMahon-Pratt, D., and Bucala, R. (2016). Leishmania-encoded orthologs of macrophage migration inhibitory factor regulate host immunity to promote parasite persistence. FASEB J. 30, 2249-2265. doi: 10.1096/fj.201500189R

Hurrell, B. P., Regli, I. B., and Tacchini-Cottier, F. (2016). Different Leishmania species drive distinct neutrophil functions. Trends Parasitol. 32, 392-401. doi: 10.1016/j.pt.2016.02.003

Hurrell, B. P., Schuster, S., Grun, E., Coutaz, M., Williams, R. A., Held, W., et al. (2015). Rapid sequestration of Leishmania mexicana by neutrophils contributes to the development of chronic lesion. PLoS Pathog. 11:e1004929. doi: 10.1371/ journal.ppat.1004929

Huynh, C., and Andrews, N. W. (2008). Iron acquisition within host cells and the pathogenicity of Leishmania. Cell Microbiol. 10, 293-300. doi: 10.1111/j.14625822.2007.01095.x

Huynh, C., Sacks, D. L., and Andrews, N. W. (2006). A Leishmania amazonensis ZIP family iron transporter is essential for parasite replication within macrophage phagolysosomes. J. Exp. Med. 203, 2363-2375. doi: 10.1084/jem. 20060559
Iborra, S., Martinez-Lopez, M., Cueto, F. J., Conde-Garrosa, R., Del Fresno, C., Izquierdo, H. M., et al. (2016). Leishmania uses mincle to target an inhibitory ITAM signaling pathway in dendritic cells that dampens adaptive immunity to infection. Immunity 45, 788-801. doi: 10.1016/j.immuni.2016. 09.012

Iniesta, V., Gomez-Nieto, L. C., and Corraliza, I. (2001). The inhibition of arginase by $\mathrm{N}$ (omega)-hydroxy-l-arginine controls the growth of Leishmania inside macrophages. J. Exp. Med. 193, 777-784. doi: 10.1084/jem.193.6.777

Jaramillo, M., Gomez, M. A., Larsson, O., Shio, M. T., Topisirovic, I., Contreras, I., et al. (2011). Leishmania repression of host translation through mTOR cleavage is required for parasite survival and infection. Cell Host Microbe 9, 331-341. doi: 10.1016/j.chom.2011.03.008

Jawed, J. J., Majumder, S., Bandyopadhyay, S., Biswas, S., Parveen, S., and Majumdar, S. (2016). SLA-PGN-primed dendritic cell-based vaccination induces Th17-mediated protective immunity against experimental visceral leishmaniasis: a crucial role of PKCbeta. Pathog. Dis. 74:ftw041. doi: 10.1093/ femspd/ftw041

Jayakumar, A., Castilho, T. M., Park, E., Goldsmith-Pestana, K., Blackwell, J. M., and McMahon-Pratt, D. (2011). TLR1/2 activation during heterologous primeboost vaccination (DNA-MVA) enhances CD8 $+\mathrm{T}$ Cell responses providing protection against Leishmania (Viannia). PLoS Negl. Trop. Dis. 5:e1204. doi: 10.1371/journal.pntd.0001204

Jebbari, H., Stagg, A. J., Davidson, R. N., and Knight, S. C. (2002). Leishmania major promastigotes inhibit dendritic cell motility in vitro. Infect. Immun. 70, 1023-1026. doi: 10.1128/IAI.70.2.1023-1026.2002

John, B., and Hunter, C. A. (2008). Immunology. Neutrophil soldiers or Trojan Horses? Science 321, 917-918. doi: 10.1126/science.1162914

Joshi, T., Rodriguez, S., Perovic, V., Cockburn, I. A., and Stager, S. (2009). B7$\mathrm{H} 1$ blockade increases survival of dysfunctional CD8(+) T cells and confers protection against Leishmania donovani infections. PLoS Pathog. 5:e1000431. doi: 10.1371/journal.ppat.1000431

Khamesipour, A., Dowlati, Y., Asilian, A., Hashemi-Fesharki, R., Javadi, A., Noazin, S., et al. (2005). Leishmanization: use of an old method for evaluation of candidate vaccines against leishmaniasis. Vaccine 23, 3642-3648. doi: 10.1016/ j.vaccine.2005.02.015

Kima, P. E., and Soong, L. (2013). Interferon gamma in leishmaniasis. Front. Immunol. 4:156. doi: 10.3389/fimmu.2013.00156

Kirchner, T., Moller, S., Klinger, M., Solbach, W., Laskay, T., and Behnen, M. (2012). The impact of various reactive oxygen species on the formation of neutrophil extracellular traps. Mediators Inflamm. 2012:849136. doi: 10.1155/ 2012/849136

Kolaczkowska, E., and Kubes, P. (2013). Neutrophil recruitment and function in health and inflammation. Nat. Rev. Immunol. 13, 159-175. doi: 10.1038/nri3399

Kropf, P., Fuentes, J. M., Fahnrich, E., Arpa, L., Herath, S., Weber, V., et al. (2005). Arginase and polyamine synthesis are key factors in the regulation of experimental leishmaniasis in vivo. FASEB J. 19, 1000-1002. doi: 10.1096/fj.043416fje

Lacerda, D. I., Cysne-Finkelstein, L., Nunes, M. P., De-Luca, P. M., Genestra Mda, S., Leon, L. L., et al. (2012). Kinetoplastid membrane protein-11 exacerbates infection with Leishmania amazonensis in murine macrophages. Mem. Inst. Oswaldo Cruz 107, 238-245. doi: 10.1590/S0074-02762012000200014

Lapara, N. J. III., and Kelly, B. L. (2010). Suppression of LPS-induced inflammatory responses in macrophages infected with Leishmania. J. Inflamm. 7:8. doi: 10. 1186/1476-9255-7-8

Laskay, T., van Zandbergen, G., and Solbach, W. (2003). Neutrophil granulocytesTrojan horses for Leishmania major and other intracellular microbes? Trends Microbiol. 11, 210-214.

Laskay, T., van Zandbergen, G., and Solbach, W. (2008). Neutrophil granulocytes as host cells and transport vehicles for intracellular pathogens: apoptosis as infection-promoting factor. Immunobiology 213, 183-191. doi: 10.1016/j.imbio. 2007.11.010

Lee, S. H., Charmoy, M., Romano, A., Paun, A., Chaves, M. M., Cope, F. O., et al. (2018). Mannose receptor high, M2 dermal macrophages mediate nonhealing Leishmania major infection in a Th1 immune environment. J. Exp. Med. 215, 357-375. doi: 10.1084/jem.20171389

Lefevre, L., Lugo-Villarino, G., Meunier, E., Valentin, A., Olagnier, D., Authier, H., et al. (2013). The C-type lectin receptors dectin-1, MR, and SIGNR3 
contribute both positively and negatively to the macrophage response to Leishmania infantum. Immunity 38, 1038-1049. doi: 10.1016/j.immuni.2013. 04.010

Leon, B., Lopez-Bravo, M., and Ardavin, C. (2007). Monocyte-derived dendritic cells formed at the infection site control the induction of protective $\mathrm{T}$ helper 1 responses against Leishmania. Immunity 26, 519-531. doi: 10.1016/j.immuni. 2007.01.017

Lodge, R., Diallo, T. O., and Descoteaux, A. (2006). Leishmania donovani lipophosphoglycan blocks NADPH oxidase assembly at the phagosome membrane. Cell Microbiol. 8, 1922-1931. doi: 10.1111/j.1462-5822.2006. 00758.x

Majumder, S., Bhattacharjee, S., Paul Chowdhury, B., and Majumdar, S. (2012). CXCL10 is critical for the generation of protective CD8 T cell response induced by antigen pulsed CpG-ODN activated dendritic cells. PLoS One 7:e48727. doi: 10.1371/journal.pone.0048727

Mandell, M. A., and Beverley, S. M. (2017). Continual renewal and replication of persistent Leishmania major parasites in concomitantly immune hosts. Proc. Natl. Acad. Sci. U.S.A. 114, E801-E810. doi: 10.1073/pnas.1619 265114

Markikou-Ouni, W., Drini, S., Bahi-Jaber, N., Chenik, M., and MeddebGarnaoui, A. (2015). Immunomodulatory effects of four Leishmania infantum potentially excreted/secreted proteins on human dendritic cells differentiation and maturation. PLoS One 10:e0143063. doi: 10.1371/journal.pone. 0143063

Marovich, M. A., McDowell, M. A., Thomas, E. K., and Nutman, T. B. (2000). IL-12p70 production by Leishmania major-harboring human dendritic cells is a CD40/CD40 ligand-dependent process. J. Immunol. 164, 5858-5865. doi: 10.4049/jimmunol.164.11.5858

Martinez-Lopez, M., Iborra, S., Conde-Garrosa, R., and Sancho, D. (2015). Batf3dependent CD103+ dendritic cells are major producers of IL-12 that drive local Th1 immunity against Leishmania major infection in mice. Eur. J. Immunol. 45, 119-129. doi: 10.1002/eji.201444651

Masic, A., Hurdayal, R., Nieuwenhuizen, N. E., Brombacher, F., and Moll, H. (2012). Dendritic cell-mediated vaccination relies on interleukin-4 receptor signaling to avoid tissue damage after Leishmania major infection of BALB/c mice. PLoS Negl. Trop. Dis. 6:e1721. doi: 10.1371/journal.pntd.0001721

Matheoud, D., Moradin, N., Bellemare-Pelletier, A., Shio, M. T., Hong, W. J., Olivier, M., et al. (2013). Leishmania evades host immunity by inhibiting antigen cross-presentation through direct cleavage of the SNARE VAMP8. Cell Host Microbe 14, 15-25. doi: 10.1016/j.chom.2013.06.003

Matos, D. C., Faccioli, L. A., Cysne-Finkelstein, L., Luca, P. M., Corte-Real, S., Armoa, G. R., et al. (2010). Kinetoplastid membrane protein-11 is present in promastigotes and amastigotes of Leishmania amazonensis and its surface expression increases during metacyclogenesis. Mem. Inst. Oswaldo Cruz 105, 341-347. doi: 10.1590/S0074-02762010000300018

Matos, I., Mizenina, O., Lubkin, A., Steinman, R. M., and Idoyaga, J. (2013). Targeting Leishmania major antigens to dendritic cells In Vivo induces protective immunity. PLoS One 8:e67453. doi: 10.1371/journal.pone. 0067453

Matte, C., Casgrain, P. A., Seguin, O., Moradin, N., Hong, W. J., and Descoteaux, A. (2016). Leishmania major promastigotes evade LC3-associated phagocytosis through the Action of GP63. PLoS Pathog. 12:e1005690. doi: 10.1371/journal. ppat. 1005690

Mendonca, S. C. (2016). Differences in immune responses against Leishmania induced by infection and by immunization with killed parasite antigen: implications for vaccine discovery. Parasit. Vectors 9:492. doi: 10.1186/s13071016-1777-x

Mittra, B., Cortez, M., Haydock, A., Ramasamy, G., Myler, P. J., and Andrews, N. W. (2013). Iron uptake controls the generation of Leishmania infective forms through regulation of ROS levels. J. Exp. Med. 210, 401-416. doi: 10.1084/jem. 20121368

Mittra, B., Laranjeira-Silva, M. F., Miguel, D. C., Perrone Bezerra de Menezes, J., and Andrews, N. W. (2017). The iron-dependent mitochondrial superoxide dismutase SODA promotes Leishmania virulence. J. Biol. Chem. 292, 12324-12338. doi: 10.1074/jbc.M116.772624

Mittra, B., Laranjeira-Silva, M. F., Perrone Bezerra de Menezes, J., Jensen, J., Michailowsky, V., and Andrews, N. W. (2016). A trypanosomatid iron transporter that regulates mitochondrial function is required for Leishmania amazonensis virulence. PLoS Pathog. 12:e1005340. doi: 10.1371/journal.ppat 1005340

Mollinedo, F., Janssen, H., de la Iglesia-Vicente, J., Villa-Pulgarin, J. A., and Calafat, J. (2010). Selective fusion of azurophilic granules with Leishmaniacontaining phagosomes in human neutrophils. J. Biol. Chem. 285, 34528-34536. doi: 10.1074/jbc.M110.125302

Mueller, S. N., and Ahmed, R. (2009). High antigen levels are the cause of T cell exhaustion during chronic viral infection. Proc. Natl. Acad. Sci. U.S.A. 106, 8623-8628. doi: 10.1073/pnas.0809818106

Muller, I., Freudenberg, M., Kropf, P., Kiderlen, A. F., and Galanos, C. (1997). Leishmania major infection in C57BL/10 mice differing at the Lps locus: a new non-healing phenotype. Med. Microbiol. Immunol. 186, 75-81. doi: 10.1007/ s004300050048

Muxel, S. M., Laranjeira-Silva, M. F., Zampieri, R. A., and Floeter-Winter, L. M. (2017). Leishmania (Leishmania) amazonensis induces macrophage miR-294 and miR-721 expression and modulates infection by targeting NOS2 and L-arginine metabolism. Sci. Rep. 7:44141. doi: 10.1038/srep44141

Nandan, D., Lo, R., and Reiner, N. E. (1999). Activation of phosphotyrosine phosphatase activity attenuates mitogen-activated protein kinase signaling and inhibits c-FOS and nitric oxide synthase expression in macrophages infected with Leishmania donovani. Infect. Immun. 67, 4055-4063.

Nandan, D., and Reiner, N. E. (1995). Attenuation of gamma interferon-induced tyrosine phosphorylation in mononuclear phagocytes infected with Leishmania donovani: selective inhibition of signaling through Janus kinases and Stat1. Infect. Immun. 63, 4495-4500.

Nandan, D., Tran, T., Trinh, E., Silverman, J. M., and Lopez, M. (2007). Identification of Leishmania fructose-1,6-bisphosphate aldolase as a novel activator of host macrophage Src homology 2 domain containing protein tyrosine phosphatase SHP-1. Biochem. Biophys. Res. Commun. 364, 601-607. doi: 10.1016/j.bbrc.2007.10.065

Nandan, D., Yi, T., Lopez, M., Lai, C., and Reiner, N. E. (2002). Leishmania EFlalpha activates the Src homology 2 domain containing tyrosine phosphatase SHP-1 leading to macrophage deactivation. J. Biol. Chem. 277, 50190-50197. doi: 10.1074/jbc.M209210200

Neves, B. M., Silvestre, R., Resende, M., Ouaissi, A., Cunha, J., Tavares, J., et al. (2010). Activation of phosphatidylinositol 3-kinase/Akt and impairment of nuclear factor-kappaB: molecular mechanisms behind the arrested maturation/activation state of Leishmania infantum-infected dendritic cells. Am. J. Pathol. 177, 2898-2911. doi: 10.2353/ajpath.2010.100367

Ng, L. G., Hsu, A., Mandell, M. A., Roediger, B., Hoeller, C., Mrass, P., et al. (2008). Migratory dermal dendritic cells act as rapid sensors of protozoan parasites. PLoS Pathog. 4:e1000222. doi: 10.1371/journal.ppat.1000222

Novais, F. O., and Scott, P. (2015). CD8+ T cells in cutaneous leishmaniasis: the good, the bad, and the ugly. Semin. Immunopathol. 37, 251-259. doi: 10.1007/ s00281-015-0475-7

Olivier, M., Brownsey, R. W., and Reiner, N. E. (1992). Defective stimulus-response coupling in human monocytes infected with Leishmania donovani is associated with altered activation and translocation of protein kinase C. Proc. Natl. Acad. Sci. U.S.A. 89, 7481-7485. doi: 10.1073/pnas.89.16.7481

Pace, D. (2014). Leishmaniasis. J. Infect. 69 (Suppl. 1), S10-S18. doi: 10.1016/j.jinf. 2014.07.016

Padigel, U. M., and Farrell, J. P. (2005). Control of infection with Leishmania major in susceptible BALB/c mice lacking the common gamma-chain for FcR is associated with reduced production of IL-10 and TGF-beta by parasitized cells. J. Immunol. 174, 6340-6345. doi: 10.4049/jimmunol.174.10.6340

Peters, N. C., Egen, J. G., Secundino, N., Debrabant, A., Kimblin, N., Kamhawi, S., et al. (2008). In vivo imaging reveals an essential role for neutrophils in Leishmaniasis transmitted by sand flies. Science 321, 970-974. doi: 10.1126/ science. 1159194

Peters, N. C., Pagán, A. J., Lawyer, P. G., Hand, T. W., Henrique Roma, E., Stamper, L. W., et al. (2014). Chronic parasitic infection maintains high frequencies of short-lived Ly6C $+\mathrm{CD} 4+$ effector $\mathrm{T}$ cells that are required for protection against re-infection. PLoS Pathog. 10:e1004538. doi: 10.1371/journal.ppat. 1004538

Pilsczek, F. H., Salina, D., Poon, K. K., Fahey, C., Yipp, B. G., Sibley, C. D., et al. (2010). A novel mechanism of rapid nuclear neutrophil extracellular trap formation in response to Staphylococcus aureus. J. Immunol. 185, 7413-7425. doi: 10.4049/jimmunol.1000675 
Plagge, M., and Laskay, T. (2017). Early production of the neutrophil-derived lipid mediators LTB4 and LXA4 is modulated by intracellular infection with Leishmania major. Biomed. Res. Int. 2017:2014583. doi: 10.1155/2017/2014583

Ponte-Sucre, A., Heise, D., and Moll, H. (2001). Leishmania major lipophosphoglycan modulates the phenotype and inhibits migration of murine Langerhans cells. Immunology 104, 462-467. doi: 10.1046/j.1365-2567. 2001.01333.x

Prina, E., Abdi, S. Z., Lebastard, M., Perret, E., Winter, N., and Antoine, J. C. (2004). Dendritic cells as host cells for the promastigote and amastigote stages of Leishmania amazonensis: the role of opsonins in parasite uptake and dendritic cell maturation. J. Cell Sci. 117(Pt 2), 315-325. doi: 10.1242/jcs.00860

Prive, C., and Descoteaux, A. (2000). Leishmania donovani promastigotes evade the activation of mitogen-activated protein kinases p38, c-Jun N-terminal kinase, and extracellular signal-regulated kinase-1/2 during infection of naive macrophages. Eur. J. Immunol. 30, 2235-2244. doi: 10.1002/1521-4141(2000) 30:8<2235::AID-IMMU2235>3.0.CO;2-9

Proudfoot, L., Nikolaev, A. V., Feng, G. J., Wei, W. Q., Ferguson, M. A., Brimacombe, J. S., et al. (1996). Regulation of the expression of nitric oxide synthase and leishmanicidal activity by glycoconjugates of Leishmania lipophosphoglycan in murine macrophages. Proc. Natl. Acad. Sci. U.S.A. 93, 10984-10989. doi: 10.1073/pnas.93.20.10984

Qi, H., Popov, V., and Soong, L. (2001). Leishmania amazonensis-dendritic cell interactions in vitro and the priming of parasite-specific $\mathrm{CD} 4(+) \mathrm{T}$ cells in vivo. J. Immunol. 167, 4534-4542. doi: 10.4049/jimmunol.167.8.4534

Rabhi, S., Rabhi, I., Trentin, B., Piquemal, D., Regnault, B., Goyard, S., et al. (2016). Lipid droplet formation, their localization and dynamics during Leishmania major macrophage infection. PLoS One 11:e0148640. doi: 10.1371/journal.pone. 0148640

Regli, I. B., Passelli, K., Hurrell, B. P., and Tacchini-Cottier, F. (2017). Survival mechanisms used by some Leishmania species to escape neutrophil killing. Front. Immunol. 8:1558. doi: 10.3389/fimmu.2017.01558

Reguera, R. M., Balana-Fouce, R., Showalter, M., Hickerson, S., and Beverley, S. M. (2009). Leishmania major lacking arginase (ARG) are auxotrophic for polyamines but retain infectivity to susceptible BALB/c mice. Mol. Biochem. Parasitol. 165, 48-56. doi: 10.1016/j.molbiopara.2009.01.001

Reiner, S. L., Zheng, S., Wang, Z. E., Stowring, L., and Locksley, R. M. (1994). Leishmania promastigotes evade interleukin 12 (IL-12) induction by macrophages and stimulate a broad range of cytokines from $\mathrm{CD} 4+\mathrm{T}$ cells during initiation of infection. J. Exp. Med. 179, 447-456. doi: 10.1084/jem.17 9.2.447

Remaley, A. T., Kuhns, D. B., Basford, R. E., Glew, R. H., and Kaplan, S. S. (1984). Leishmanial phosphatase blocks neutrophil O-2 production. J. Biol. Chem. 259, $11173-11175$.

Revest, M., Donaghy, L., Cabillic, F., Guiguen, C., and Gangneux, J. P. (2008). Comparison of the immunomodulatory effects of $L$. donovani and $L$. major excreted-secreted antigens, particulate and soluble extracts and viable parasites on human dendritic cells. Vaccine 26, 6119-6123. doi: 10.1016/j.vaccine.2008. 09.005

Rhee, E. G., Mendez, S., Shah, J. A., Wu, C. Y., Kirman, J. R., Turon, T. N., et al. (2002). Vaccination with heat-killed leishmania antigen or recombinant leishmanial protein and $\mathrm{CpG}$ oligodeoxynucleotides induces longterm memory $\mathrm{CD} 4+$ and $\mathrm{CD} 8+\mathrm{T}$ cell responses and protection against leishmania major infection. J. Exp. Med. 195, 1565-1573. doi: 10.1084/jem. 20020147

Ribeiro-Gomes, F. L., Peters, N. C., Debrabant, A., and Sacks, D. L. (2012). Efficient capture of infected neutrophils by dendritic cells in the skin inhibits the early anti-leishmania response. PLoS Pathog. 8:e1002536. doi: 10.1371/journal.ppat. 1002536

Ribeiro-Gomes, F. L., Romano, A., Lee, S., Roffe, E., Peters, N. C., Debrabant, A., et al. (2015). Apoptotic cell clearance of Leishmania major-infected neutrophils by dendritic cells inhibits CD8(+) T-cell priming in vitro by Mer tyrosine kinase-dependent signaling. Cell Death Dis. 6:e2018. doi: 10.1038/cddis.20 15.351

Ricardo-Carter, C., Favila, M., Polando, R. E., Cotton, R. N., Bogard Horner, K., Condon, D., et al. (2013). Leishmania major inhibits IL-12 in macrophages by signalling through CR3 (CD11b/CD18) and down-regulation of ETSmediated transcription. Parasite Immunol. 35, 409-420. doi: 10.1111/pim. 12049
Ritter, U., Frischknecht, F., and van Zandbergen, G. (2009). Are neutrophils important host cells for Leishmania parasites? Trends Parasitol. 25, 505-510. doi: $10.1016 /$ j.pt.2009.08.003

Rochael, N. C., Guimaraes-Costa, A. B., Nascimento, M. T., DeSouza-Vieira, T. S., Oliveira, M. P., Garcia e Souza, L. F., et al. (2015). Classical ROS-dependent and early/rapid ROS-independent release of neutrophil extracellular traps triggered by Leishmania parasites. Sci. Rep. 5:18302. doi: 10.1038/srep18302

Rogers, M., Kropf, P., Choi, B. S., Dillon, R., Podinovskaia, M., Bates, P., et al. (2009). Proteophosophoglycans regurgitated by Leishmania-infected sand flies target the L-arginine metabolism of host macrophages to promote parasite survival. PLoS Pathog. 5:e1000555. doi: 10.1371/journal.ppat.1000555

Romano, A., Doria, N. A., Mendez, J., Sacks, D. L., and Peters, N. C. (2015). Cutaneous infection with Leishmania major mediates heterologous protection against visceral infection with Leishmania infantum. J. Immunol. 195, 3816-3827. doi: 10.4049/jimmunol.1500752

Roy, K., Mandloi, S., Chakrabarti, S., and Roy, S. (2016). Cholesterol corrects altered conformation of MHC-II protein in Leishmania donovani infected macrophages: implication in therapy. PLoS Negl. Trop. Dis. 10:e0004710. doi: 10.1371/journal.pntd.0004710

Roy, S., Gupta, P., Palit, S., Basu, M., Ukil, A., and Das, P. K. (2017). The role of $\mathrm{PD}-1$ in regulation of macrophage apoptosis and its subversion by Leishmania donovani. Clin. Transl. Immunol. 6:e137. doi: 10.1038/cti.2017.12

Roy, S., and Mandal, C. (2016). Leishmania donovani utilize sialic acids for binding and phagocytosis in the macrophages through selective utilization of siglecs and impair the innate immune arm. PLoS Negl. Trop. Dis. 10:e0004904. doi: 10.1371/journal.pntd.0004904

Ruhland, A., and Kima, P. E. (2009). Activation of PI3K/Akt signaling has a dominant negative effect on IL-12 production by macrophages infected with Leishmania amazonensis promastigotes. Exp. Parasitol. 122, 28-36. doi: 10. 1016/j.exppara.2008.12.010

Sacks, D., and Noben-Trauth, N. (2002). The immunology of susceptibility and resistance to Leishmania major in mice. Nat. Rev. Immunol. 2, 845-858. doi: $10.1038 /$ nri933

Sacks, D. L. (2014). Vaccines against tropical parasitic diseases: a persisting answer to a persisting problem. Nat. Immunol. 15, 403-405. doi: 10.1038/ni.2853

Saha, B., Das, G., Vohra, H., Ganguly, N. K., and Mishra, G. C. (1995). Macrophage- $\mathrm{T}$ cell interaction in experimental visceral leishmaniasis: failure to express costimulatory molecules on Leishmania-infected macrophages and its implication in the suppression of cell-mediated immunity. Eur. J. Immunol. 25, 2492-2498. doi: 10.1002/eji.1830250913

Salei, N., Hellberg, L., Kohl, J., and Laskay, T. (2017). Enhanced survival of Leishmania major in neutrophil granulocytes in the presence of apoptotic cells. PLoS One 12:e0171850. doi: 10.1371/journal.pone.0171850

Saljoughian, N., Taheri, T., and Rafati, S. (2014). Live vaccination tactics: possible approaches for controlling visceral leishmaniasis. Front. Immunol. 5:134. doi: 10.3389/fimmu. 2014.00134

Sanabria, M. X., Vargas-Inchaustegui, D. A., Xin, L., and Soong, L. (2008). Role of natural killer cells in modulating dendritic cell responses to Leishmania amazonensis infection. Infect. Immun. 76, 5100-5109. doi: 10.1128/IAI.00 438-08

Sancho, D., and Reis e Sousa, C. (2012). Signaling by myeloid C-type lectin receptors in immunity and homeostasis. Annu. Rev. Immunol. 30, 491-529. doi: 10.1146/annurev-immunol-031210-101352

Sancho, D., and Reis e Sousa, C. (2013). Sensing of cell death by myeloid C-type lectin receptors. Curr. Opin. Immunol. 25, 46-52. doi: 10.1016/j.coi.2012.12.007

Sano, G., Hafalla, J. C., Morrot, A., Abe, R., Lafaille, J. J., and Zavala, F. (2001). Swift development of protective effector functions in naive $\mathrm{CD} 8(+) \mathrm{T}$ cells against malaria liver stages. J. Exp. Med. 194, 173-180. doi: 10.1084/jem.194.2.173

Sarkar, A., Aga, E., Bussmeyer, U., Bhattacharyya, A., Moller, S., Hellberg, L., et al. (2013). Infection of neutrophil granulocytes with Leishmania major activates ERK 1/2 and modulates multiple apoptotic pathways to inhibit apoptosis. Med. Microbiol. Immunol. 202, 25-35. doi: 10.1007/s00430-012-0246-1

Savina, A., Jancic, C., Hugues, S., Guermonprez, P., Vargas, P., Moura, I. C., et al. (2006). NOX2 controls phagosomal $\mathrm{pH}$ to regulate antigen processing during crosspresentation by dendritic cells. Cell 126, 205-218. doi: 10.1016/j.cell.2006. 05.035

Schwarz, T., Remer, K. A., Nahrendorf, W., Masic, A., Siewe, L., Müller, W., et al. (2013). T cell-derived IL-10 determines leishmaniasis disease outcome 
and is suppressed by a dendritic cell based vaccine. PLoS Pathog. 9:e1003476. doi: 10.1371/journal.ppat.1003476

Scianimanico, S., Desrosiers, M., Dermine, J. F., Meresse, S., Descoteaux, A. and Desjardins, M. (1999). Impaired recruitment of the small GTPase rab7 correlates with the inhibition of phagosome maturation by Leishmania donovani promastigotes. Cell Microbiol. 1, 19-32. doi: 10.1046/j.1462-5822. 1999.00002.x

Scott, P., Natovitz, P., Coffman, R. L., Pearce, E., and Sher, A. (1988). Immunoregulation of cutaneous leishmaniasis. $\mathrm{T}$ cell lines that transfer protective immunity or exacerbation belong to different $\mathrm{T}$ helper subsets and respond to distinct parasite antigens. J. Exp. Med. 168, 1675-1684. doi: 10.1084/ jem.168.5.1675

Seguin, O., and Descoteaux, A. (2016). Leishmania, the phagosome, and host responses: The journey of a parasite. Cell Immunol. 309, 1-6. doi: 10.1016/j. cellimm.2016.08.004

Severn, A., Wakelam, M. J., and Liew, F. Y. (1992). The role of protein kinase $\mathrm{C}$ in the induction of nitric oxide synthesis by murine macrophages. Biochem. Biophys. Res. Commun. 188, 997-1002. doi: 10.1016/0006-291X(92) 91330-S

Shweash, M., Adrienne, McGachy, H., Schroeder, J., Neamatallah, T., Bryant, C. E., et al. (2011). Leishmania mexicana promastigotes inhibit macrophage IL-12 production via TLR-4 dependent COX-2, iNOS and arginase-1 expression. Mol. Immunol. 48, 1800-1808. doi: 10.1016/j.molimm.2011.05.013

Silverman, J. M., Clos, J., Horakova, E., Wang, A. Y., Wiesgigl, M., Kelly, I., et al. (2010). Leishmania exosomes modulate innate and adaptive immune responses through effects on monocytes and dendritic cells. J. Immunol. 185, 5011-5022. doi: 10.4049/jimmunol.1000541

Soong, L. (2008). Modulation of dendritic cell function by Leishmania parasites. J. Immunol. 180, 4355-4360. doi: 10.4049/jimmunol.180.7.4355

Srivastav, S., Kar, S., Chande, A. G., Mukhopadhyaya, R., and Das, P. K. (2012). Leishmania donovani exploits host deubiquitinating enzyme A20, a negative regulator of TLR signaling, to subvert host immune response. J. Immunol. 189, 924-934. doi: 10.4049/jimmunol.1102845

Srivastav, S., Saha, A., Barua, J., Ukil, A., and Das, P. K. (2015). IRAK-M regulates the inhibition of TLR-mediated macrophage immune response during late in vitro Leishmania donovani infection. Eur. J. Immunol. 45, 2787-2797. doi: 10.1002/eji.201445336

Stäger, S., and Rafati, S. (2012). CD8(+) T cells in Leishmania infections: friends or foes? Front. Immunol. 3:5. doi: 10.3389/fimmu.2012.00005

Sypek, J. P., Chung, C. L., Mayor, S. E., Subramanyam, J. M., Goldman, S. J., Sieburth, D. S., et al. (1993). Resolution of cutaneous leishmaniasis: interleukin 12 initiates a protective T helper type 1 immune response. J. Exp. Med. 177, 1797-1802. doi: 10.1084/jem.177.6.1797

Tachado, S. D., Gerold, P., Schwarz, R., Novakovic, S., McConville, M., and Schofield, L. (1997). Signal transduction in macrophages by glycosylphosphatidylinositols of Plasmodium, Trypanosoma, and Leishmania: activation of protein tyrosine kinases and protein kinase $\mathrm{C}$ by inositolglycan and diacylglycerol moieties. Proc. Natl. Acad. Sci. U.S.A. 94, 4022-4027. doi: 10.1073/pnas.94.8.4022

Tiwari, N., Kumar, V., Gedda, M. R., Singh, A. K., Singh, V. K., Gannavaram, S., et al. (2017). Identification and characterization of miRNAs in response to Leishmania donovani infection: delineation of their roles in macrophage dysfunction. Front. Microbiol. 8:314. doi: 10.3389/fmicb.2017. 00314

Uzonna, J. E., Wei, G., Yurkowski, D., and Bretscher, P. (2001). Immune elimination of Leishmania major in mice: implications for immune memory, vaccination, and reactivation disease. J. Immunol. 167, 6967-6974. doi: 10.4049/ jimmunol.167.12.6967

van Zandbergen, G., Hermann, N., Laufs, H., Solbach, W., and Laskay, T. (2002). Leishmania promastigotes release a granulocyte chemotactic factor and induce interleukin-8 release but inhibit gamma interferon-inducible protein 10 production by neutrophil granulocytes. Infect. Immun. 70, 4177-4184. doi: 10.1128/IAI.70.8.4177-4184.2002

van Zandbergen, G., Klinger, M., Mueller, A., Dannenberg, S., Gebert, A., Solbach, W., et al. (2004). Cutting edge: neutrophil granulocyte serves as a vector for Leishmania entry into macrophages. J. Immunol. 173, 6521-6525. doi: 10.4049/jimmunol.173.11.6521

Verma, J. K., Rastogi, R., and Mukhopadhyay, A. (2017). Leishmania donovani resides in modified early endosomes by upregulating Rab5a expression via the downregulation of miR-494. PLoS Pathog. 13:e1006459. doi: 10.1371/journal. ppat.1006459

Vinet, A. F., Fukuda, M., Turco, S. J., and Descoteaux, A. (2009). The Leishmania donovani lipophosphoglycan excludes the vesicular proton-ATPase from phagosomes by impairing the recruitment of synaptotagmin V. PLoS Pathog. 5:e1000628. doi: 10.1371/journal.ppat. 1000628

von Stebut, E. (2017). Parasites dampen dendritic cell activation to ensure their survival. Trends Parasitol. 33, 78-80. doi: 10.1016/j.pt.2016.12.001

von Stebut, E., Belkaid, Y., Jakob, T., Sacks, D. L., and Udey, M. C. (1998). Uptake of Leishmania major amastigotes results in activation and interleukin 12 release from murine skin-derived dendritic cells: implications for the initiation of anti-Leishmania immunity. J. Exp. Med. 188, 1547-1552. doi: 10.1084/jem. 188. 8.1547

Wanderley, J. L., Moreira, M. E., Benjamin, A., Bonomo, A. C., and Barcinski, M. A. (2006). Mimicry of apoptotic cells by exposing phosphatidylserine participates in the establishment of amastigotes of Leishmania (L) amazonensis in mammalian hosts. J. Immunol. 176, 1834-1839. doi: 10.4049/jimmunol.176. 3.1834

Weingartner, A., Kemmer, G., Muller, F. D., Zampieri, R. A., Gonzaga dos Santos, M., Schiller, J., et al. (2012). Leishmania promastigotes lack phosphatidylserine but bind annexin $\mathrm{V}$ upon permeabilization or miltefosine treatment. PLoS One 7:e42070. doi: 10.1371/journal.pone.0042070

Wenzel, A., and Van Zandbergen, G. (2009). Lipoxin A4 receptor dependent Leishmania infection. Autoimmunity 42, 331-333. doi: 10.1080/08916930902 828239

Wilson, J., Huynh, C., Kennedy, K. A., Ward, D. M., Kaplan, J., Aderem, A., et al. (2008). Control of parasitophorous vacuole expansion by LYST/Beige restricts the intracellular growth of Leishmania amazonensis. PLoS Pathog. 4:e1000179. doi: 10.1371/journal.ppat.1000179

Winberg, M. E., Holm, A., Sarndahl, E., Vinet, A. F., Descoteaux, A., Magnusson, K. E., et al. (2009). Leishmania donovani lipophosphoglycan inhibits phagosomal maturation via action on membrane rafts. Microbes Infect. 11, 215-222. doi: 10.1016/j.micinf.2008.11.007

Woelbing, F., Kostka, S. L., Moelle, K., Belkaid, Y., Sunderkoetter, C., Verbeek, S., et al. (2006). Uptake of Leishmania major by dendritic cells is mediated by Fc gamma receptors and facilitates acquisition of protective immunity. J. Exp. Med. 203, 177-188. doi: 10.1084/jem.20052288

Xin, L., Li, K., and Soong, L. (2008). Down-regulation of dendritic cell signaling pathways by Leishmania amazonensis amastigotes. Mol. Immunol. 45, 3371-3382. doi: 10.1016/j.molimm.2008.04.018

Xin, L., Li, Y., and Soong, L. (2007). Role of interleukin-1beta in activating the CD11c(high) CD45RB- dendritic cell subset and priming Leishmania amazonensis-specific CD4+ T cells in vitro and in vivo. Infect. Immun. 75, 5018-5026. doi: 10.1128/IAI.00499-07

Yang, Z., Mosser, D. M., and Zhang, X. (2007). Activation of the MAPK, ERK, following Leishmania amazonensis infection of macrophages. J. Immunol. 178, 1077-1085. doi: 10.4049/jimmunol.178.2.1077

Yizengaw, E., Getahun, M., Tajebe, F., Cruz Cervera, E., Adem, E., Mesfin, G., et al. (2016). Visceral Leishmaniasis patients display altered composition and maturity of neutrophils as well as impaired neutrophil effector functions. Front. Immunol. 7:517. doi: 10.3389/fimmu.2016.00517

Zagorska, A., Traves, P. G., Lew, E. D., Dransfield, I., and Lemke, G. (2014). Diversification of TAM receptor tyrosine kinase function. Nat. Immunol. 15, 920-928. doi: 10.1038/ni.2986

Zaph, C., Uzonna, J., Beverley, S. M., and Scott, P. (2004). Central memory T cells mediate long-term immunity to Leishmania major in the absence of persistent parasites. Nat. Med. 10, 1104-1110. doi: 10.1038/nm1108

Conflict of Interest Statement: The authors declare that the research was conducted in the absence of any commercial or financial relationships that could be construed as a potential conflict of interest.

Copyright $\odot 2018$ Martínez-López, Soto, Iborra and Sancho. This is an open-access article distributed under the terms of the Creative Commons Attribution License (CC BY). The use, distribution or reproduction in other forums is permitted, provided the original author(s) and the copyright owner are credited and that the original publication in this journal is cited, in accordance with accepted academic practice. No use, distribution or reproduction is permitted which does not comply with these terms. 